KELLER, Damián; LAZZARINI, Victor. 2017. Theoretical Approaches to Musical Creativity: The Ubimus Perspective. MUSICA THEORICA. Salvador: TeMA, 201701, p. 1-53.

MUSICA THEORICA 201701

SCIENTIFIC ARTICLE

Data do recebimento: $27 / 06 / 2017$

Data da aprovação final:31/07/2017

\title{
Theoretical Approaches to Musical Creativity: The Ubimus Perspective
}

\author{
Abordagem Teórica à Criatividade Musical: \\ A Perspectiva Ubimus
}

\section{Damián Keller}

Núcleo Amazônico de Pesquisa Musical

Universidade Federal do Acre e Instituto Federal do Acre

dkeller@ccrma.stanford.edu

\section{Victor Lazzarini}

Maynooth University

victor.lazzarini@nuim.ie

\begin{abstract}
We tackle the theoretical implications of an emergent field of study, ubiquitous music (ubimus). Striving to place musical research within the wider field of creativity studies, this paper covers theoretical background and critical discussions of three music creativity models - a model proposed by Mannis (2014), the In-group, Out-group model (MDF - Ferraz and Keller 2014) and the ecologically grounded perspective (Keller and Lazzarini 2017). Data and on-site observations of creative activities provide the raw materials to test musical theories. Recent ubiquitous music research features multiple experimental initiatives, involving children (Pereira et al. in press), adolescents (Lima et al. 2012) or the elderly, and targeting trained musicians (Ferreira et al.2015), novices (Miletto et al. 2011) and cognitively challenged adults. We chose three ubimus studies to exemplify empirical research that brings to light issues that have not been considered by some of the current theoretical approaches to musical creativity.
\end{abstract}

Keywords: musical creativity; ubiquitous music; experimental music.

Resumo: Abordamos as implicações teóricas de um campo de estudos emergente - a música ubíqua (ubimus). Buscando situar a pesquisa musical dentro dos estudos sobre criatividade, este artigo abrange o substrato teórico e as discussões críticas de três modelos de criatividade musical - um modelo proposto por Mannis (2014), o Modelo Dentro-Fora (MDF - Ferraze Keller 2014) e a perspectiva ecológica (Keller e Lazzarini 2017). Os dados e as observações in loco de atividades criativas forneceram materiais brutos para testarmos teorias musicais. Pesquisas recentes em música ubíqua concentram-se em múltiplas iniciativas experimentais, envolvendo crianças (Pereira et al. no prelo), adolescentes (Lima et al. 2012) ou idosos, e focando em músicos

\section{MUSICA THEORICA}


KELLER, Damián; LAZZARINI, Victor. 2017. Theoretical Approaches to Musical Creativity: The Ubimus Perspective. MUSICA THEORICA. Salvador: TeMA, 201701, p. 1-53.

profissionais (Ferreira et al. 2015), iniciantes (Miletto et al. 2011) e adultos com deficiências cognitivas. Escolhemos três estudos em música ubíqua para exemplificar as pesquisas empíricas que trazem à luz problemas que ainda não foram tratados desde as perspectivas teóricas da criatividade musical.

Palavras-chave: criatividade musical; música ubíqua; música experimental

\title{
1 - Introduction
}

Although computers have been used within the context of creative musical practices since the early days of computer science (Lazzarini 2013), technology-based creative music research still presents serious methodological difficulties. On the one hand, general creativity theories have seldom been applied to study creative musical phenomena in real-world settings. On the other, computer science research has generally targeted the support of music production (e. g., sound synthesis, real time control, graphic user interface design) rather than address the users' needs within the context of creative activities (Eaglestone et al. 2007), leading to a less than ideal connection between the advancement of technological tools and music creation. Upton and coauthors' (2005) bleak assessments of the state of the art still holds true:

\begin{abstract}
There is currently a lack of a research base for electroacoustic composition systems. Studies have been mainly restricted to 'traditional' tonal Western Art Music. The search for objective models of composition is also exacerbated by sparsity of insightful research into creativity, particularly from a software perspective. Appropriate methodology is also problematic because of the difficulty of determining the cognitive processes of composers. Further, derivation and validation of models requires empirical studies, but these have rarely been used to research composition. The [...] experimental studies that exist fail to address interaction with computer systems, or to address the complexities of professional composition. Few go beyond trivial composition exercises using crude and simple sound sources (Upton et al. 2005).
\end{abstract}

Since 2007, the Ubiquitous Music Group has been engaged in a multidisciplinary effort to investigate the creative potential of converging forms of social interaction, mobile and distributed technologies and materially grounded artistic practices. We have proposed the adoption of the term 'ubiquitous music' (ubimus) to define practices that empower participants of musical experiences through socially oriented, creativity-enhancing tools (Keller et al. 2014a). A consensual definition, established through collaborative work within our community of practice, summarizes the research efforts of three distinct but complementary methodological approaches within the field: (1) the computational perspective, (2) the dialogical view, and (3) the ecologically 
grounded framework. The computational perspective targets the development of computational tools for supporting ubiquitous musical activities by nonmusicians (Flores et al. 2014; Lazzarini et al. 2012; Miletto et al. 2011; Pimenta et al. 2012), proposing design patterns and metaphors for interaction to boost creativity. The dialogical approach focuses on the educational and philosophical issues raised by ubimus practice, highlighting the applicability of research methods grounded on the Brazilian educational movement (Brown et al. 2014; Lima et al. 2012) and impacting the area of participatory design (Keller et al. 2014). The ecologically grounded perspective proposes the fusion of creativity studies with ubiquitous music practices, signaling a path toward the application of experimental ubimus research to increase our understanding of creative phenomena in everyday settings (Keller et al. 2010; Keller et al. 2014b; Keller and Lazzarini 2017). This approach has fostered a surge of methodological and empirical questions around the emerging field of everyday musical creativity studies (Pinheiro da Silva et al. 2013; Keller et al. 2013a; Keller and Lima 2016).

Despite mutual acknowledgments and ongoing exchanges, such as those documented in the context of the Ubiquitous Music Workshops (2010-2016), the computational approach, the educational view and the ecological perspective are only loosely connected. On one hand, this keeps the flow of ideas afresh, allowing for diverse - and sometimes contradictory - views to coexist. On the other hand, an implicit eclecticism prevents the application of theory-driven empirical work, precluding the use of previous knowledge to tackle new research problems. Symptoms of this limitation are particularly prominent when designing new experiments. What are the most important variables to be assessed during creative activities? How are the creative products related to the computational infrastructure? What is the impact of previous educational experiences on the potential for group-based musical creativity? Last but not least, another ongoing interrogation in current ubimus research is whether the computational support should be targeted toward domain-specific or general creativity factors.

This paper tackles musical creativity models, highlighting an emergent ecological perspective within the context of ubimus research. The first section provides a theoretical background necessary to place musical research within the wider field of creativity studies. Hopefully, the contributions provided by the ubimus experiments reported in this paper may nurture advances in creativity studies. The second section features critical discussions of three creativity models applicable to music making: a model proposed by Mannis (2014), the In-group, Out-group model (MDF - Ferraz and Keller 2014) and the ecologically grounded perspective (Keller and Lazzarini 2017). To ensure the applicability of the theoretical proposals, experimental methods are needed to provide data and onsite observations of creative activities. Ubiquitous music research - outlined in the third section - features multiple examples of experimental initiatives, 
encompassing a diversity of participants - from children (Pereira et al. in press) to adolescents (Lima et al. 2012) to the elderly, including trained musicians (Ferreira et al. 2015), novices (Miletto et al. 2011) and cognitively challenged adults (Silva et al. 2016). Given the focus on music-theoretical proposals, we have chosen three empirical studies that exemplify emergent issues in ubimus research. Case 1 encompasses multiple studies targeting everyday manifestations of musical creativity. Case 2 describes a study that brings together musicians and casual participants doing improvisatory sessions in a non-traditional venue. Finally, case 3 reproduces the findings of a longitudinal study involving the elaboration of a multimodal installation by three artists. The outcomes of these experiments are discussed in the fifth section of the paper. Here, the theoretical issues raised by the creativity models laid out in section 2 are set against the experimental results. We highlight the potential for applications in empirically grounded music theory and indicate the limitations of the adopted creativity support methods. The final section summarizes the findings and lays out possible avenues for future research.

\section{$\underline{\text { PART } 1}$}

\section{2 - Issues in Creativity Studies}

The magnitude or scope of creativity separates creative outcomes according to their level of achievement. According to (Beghetto and Kaufman 2007; Kaufman and Beghetto 2009), creativity magnitudes encompass four categories: Big-c, pro-c, little-c and mini-c (Kozbelt et al. 2010, p. 23) (Table 1). Bigc or eminent creativity are manifestations socially established as paradigmatic examples of creative outcomes. Typical examples are published works of art and scientific theories. Eminent creativity manifestations necessarily target creative products, thus professional products that do not involve wide social exposure are excluded from this class. Personal experiences that lead to creative products are treated within the context of everyday or little-c creativity studies (Richards et al. 1988). Kaufman and Beghetto (2009) provide a finer distinction among everyday creative phenomena by introducing the mini-c category. Mini-c creativity involves internal, subjective and emotional aspects of everyday creativity. Thus, the little-c label is reserved for everyday creative phenomena that yield creative products, while the mini-c label is used for outcomes that do not yield material products. Between little-c and Big-c phenomena, Kaufman and Beghetto (2009) suggest another creativity magnitude: professional creativity or pro-c. Pro-c studies focus on professional creative achievements that do not attain widespread recognition to be labelled as eminent creativity. 


\begin{tabular}{|c|c|l|c|}
\hline label & magnitude & \multicolumn{1}{|c|}{ description } & label \\
\hline Big-c & eminent creativity & Socially acknowledged creative performance & Big-c \\
\hline pro-c & $\begin{array}{r}\text { professional } \\
\text { creativity }\end{array}$ & $\begin{array}{l}\text { Creative performance that does not } \\
\text { necessarily imply widespread recognition }\end{array}$ & pro-c \\
\hline little-c & everyday creativity & Personal creative performance & little-c \\
\hline
\end{tabular}

Tabel 1: Creativity magnitudes: the four-c model (Beghetto and Kaufman 2007; Kaufman and Beghetto 2009)

Theories of creative performance focus on unambiguously creative behavior. Hence, they try to link creativity factors to creative processes and products by studying the outcomes of the creative activity. Contrastingly, studies of creative potentials strive to identify factors that foster or suppress creativity in individuals and human groups. Thus, the focus is on unfulfilled possibilities rather than on actual creative results. Runco's (2007) two-level hierarchy divides creativity theories into two groups: 1. those that deal with creative potential; and 2. those that focus on creative performance (Table 2). Within the former class of theories, some approaches deal with factors related to personality (person) and to places (also called environmental pressures or press). Theories that focus on potentials open opportunities for research on predictors, i.e., variables that influence creative outcomes. Examples of predictors are: personality traits, environmental pressures (impacting long-term and short-term adaptations) and cognitive and social resources available for creative activities (included within the process factors in Runco's two-level hierarchy).

\begin{tabular}{|c|c|c|}
\hline Level 1 & c-potential & c-performance \\
\hline \multirow{2}{*}{ Level 2 } & person & products \\
\cline { 2 - 3 } & process & persuasion \\
\cline { 2 - 3 } & press / place & interactions (among c-factors) \\
\hline
\end{tabular}

Tabel 2: Creativity factors according to Runco (2007)

Runco's two-tier framework incorporates one of the most influential classifications of the basic elements of creativity, the 4Ps: person, product, process and press (Rhodes 1961). Rhodes (1961, p. 305) proposed that "the word creativity is a noun naming the phenomenon in which a person communicates a new concept (which is the product). Mental activity (or mental process) is implicit in the definition, and of course no one could conceive of a person living or operating in a vacuum, so the term press is also implicit." This classification was later expanded by Kozbelt et al. (2010) to include creative potentials (Runco 2004) and persuasion (Simonton 1990). Proposals that focus on persuasion view creativity as the result of the ability of individuals to influence the direction taken by a creative 
domain. These proposals stress the social value of the creative products, excluding manifestations that focus on personal or subjective aspects of creativity.

More recently, a sociocultural approach has been laid out by Glăveanu (2013). Glăveanu's 5As framework features a systemic relationship among three stakeholders: actors, audiences and artifacts (Table 3). In this sociocultural model, creativity is concerned with the action of an actor or a group of actors, interacting with other actors (audiences) and with the material world. The creative exchange is done through affordances (Gibson 1977) leading to the generation of new and useful artifacts, which feature modified affordances. While actors engage in creative actions, they produce are share artifacts with an audience. These actions are done within cultural and social contexts which foster and constrain the creative behaviors.

\begin{tabular}{|c|l|c|l|}
\hline 4Ps factors & \multicolumn{1}{|c|}{ description } & 5As factors & \multicolumn{1}{c|}{ description } \\
\hline person & internal attributes of the person & actor & $\begin{array}{l}\text { personal attributes in relation to } \\
\text { the social context }\end{array}$ \\
\hline process & cognitive mechanisms & action & $\begin{array}{l}\text { coordinated psychological and } \\
\text { behavioural manifestations }\end{array}$ \\
\hline product & $\begin{array}{l}\text { features of physical objects or } \\
\text { the consensus around them }\end{array}$ & artifact & $\begin{array}{l}\text { Cultural context of artifact } \\
\text { production and evaluation }\end{array}$ \\
\hline place press & $\begin{array}{l}\text { the social as an external set of } \\
\text { variables }\end{array}$ & place press & $\begin{array}{l}\text { the social as an external set of } \\
\text { variables }\end{array}$ \\
\cline { 2 - 4 } & & affordances & $\begin{array}{l}\text { The interdependence between the } \\
\text { creators and the material world }\end{array}$ \\
\hline
\end{tabular}

Table 3: Glăveanu's 5As sociocultural proposal and the 4Ps framework (after Glăveanu's 2013)

A comparison of the $5 \mathrm{As}$ with the $4 \mathrm{Ps}$ framework highlights the former's emphasis on the social and material context of the creative act (Table 3). While person stands for the individual's characteristics, actor stresses the factors that connect the individual with her social context. Process focuses on the cognitive mechanisms involved during creative activities. Contrastingly, action implies a tight integration of cognition and behavior, pointing to an embedded-embodied view of cognition (Gibson 1979). Product - which describes the features and the consensus built around creative results - is replaced by artifact, encompassing both the material and the behavioral results of creative activity within a specific cultural context. Place or press defines a set of external variables that condition creative activity. This factor is replaced by audiences and affordances, underlining the interdependence of the stakeholders' actions with their social and material world. 


\section{3 - Theoretical Approaches to Musical Creativity}

Recent models of musical creativity have focused on domain-specific aspects of creativity. As summarized in Keller (2013), current musical creativity practices follow three trends:

1. Approaches centered on acoustic-instrumental aspects: rooted on the nineteenth-century tradition of instrumental music, it focuses on professional and eminent creativity. This view has been adopted by the majority of proposals in digital musical instrument development (see NIME - New Instruments for Musical Expression for multiple examples). While breaking some new ground in terms of seizing the interactive potential of new technologies, it is a continuation of a long-standing paradigm.

2. Approaches centered on algorithmic aspects: this trend is grounded on the early work on Artificial Intelligence and has had a heavy influence on computer music practices (McCormack 2012; Nierhaus 2009; Coelho de Souza and Faria 2012). Current proposals have moved beyond the early attempts to reproduce stylistic characteristics of instrumental music - as exemplified in the pioneering work by Hiller and Isaacson (1959) and in the multiple style-oriented studies produced by Cope (2004).

3. Approaches centered on human aspects: this perspective gathers contributions from information technology creative practices (Mitchell et al. 2003), interaction esthetics (Löwgren 2009) and ecologically grounded creative practices (Keller 2012; Keller and Capasso 2006; Keller and Lazzarini 2017).

Each of these perspectives furnishes concepts, methods and tools for music making. But their specific contributions to theoretically driven research on creative practice are still unclear. There are at least two aspects to be considered. Firstly, despite the complex relationships between the models and the data analysis - as will be addressed in the discussion below - the proposals should strive for validation through actual deployments. A tight bond between a model and a data gathering and analysis process increases the weight of the theory. Ideally, a model should be falsifiable and replicable. It should be possible to establish its range of applications. Nevertheless, the elusiveness of the objects of creativity studies usually precludes clear-cut boundaries. Creative practice yields products and processes that cannot be defined a priori. This means that the validity of a theory cannot be limited to the extant musical repertoire. Creativity support tools should allow room for new ways of music making. If a musical model is turned into a prescriptive tool, the artistic results may be satisfactory, but not creative. 
The second aspect to be considered is the relationship between the proposed music theory and the state-of-the-art views on creativity. The dialogue between musically minded creativity theorizing and the broader area of creativity studies has been scant. It could be argued that the methods employed in areas prone to formalization - such as engineering - are not easily translatable to the artistic realm. A common mistake is to try to apply the recipes of problem solving to every creativity domain (Newell et al. 1958). Problem-solving demands a clear specification of a goal at an initial stage of the creative cycle. While this is possible in some forms of music making - such as in rule-based instrumental counterpoint writing - it can hardly be applied to the wide range of twenty-first century musical practices.

More generally, current discussions in creativity theory try to untangle domain-specific and general creativity factors (Baer 2015; Kaufman and Baer 2005). With few exceptions (Katz and Gardner 2012), this issue has been ignored in music theorizing. For example, the acoustic-instrumental approach takes as a given that all forms of music making adopt a simplified form of sonic parameter mapping: discrete pitches (preferably following the standard temperament), discrete durations (ideally represented as notes and generally within a meterbased representation) and a predefined set of timbres (usually emulating acoustic instrumental sources) ${ }^{1}$. Furthermore, almost all forms of musical interaction within this perspective are based on bodily gestures. While the latter constraint is well suited for technologies that try to reproduce the behavior of acoustic musical instruments, other approaches to music making - such as those based on technological or environmental resources for creative actions - are not amenable to an anthropocentric approach. Given this context, we will analyze whether the music creativity models under discussion meet at least two criteria:

1. do they provide a set of variables that can be observed through actual deployments? And...

2. do they take into account the factors that impact the creative activity beyond a narrow musical domain?

\section{4 - Ecologically ground ed creative practice}

In the late 1990s, the application of embedded-embodied theories on cognition (Clark 1999; Gibson 1979) laid out a path to an alternative view of musical creativity. Windsor (1995) and Keller (1999a; 2000) provided the initial coverage of the embedded-embodied approach to music making and music

\footnotetext{
${ }^{1}$ Wishart employs the term lattice-based music for the products of this aesthetic approach.
} 
perception literature. Through an acute and highly critical essay, Windsor (1995) brought several ecological concepts into the realm of musical analysis. His proposal - although tuned to the demands of studio-centered electroacoustic practice - highlighted the close affinity between sonic art practices and ecologically oriented theoretical efforts. Working independently from a complementary perspective, Keller and Truax (1998) proposed a Gibsonean approach to music making. Ecologically grounded synthesis techniques were presented as a proof of concept of the applicability of the embedded-embodied view on cognition within the context of creative music making.

A series of artistic projects by the Capasso+Keller+Tinajero Collective (1997-2001) (Keller and Capasso 2000) unveiled several shortcomings in the existing music-theoretical tools. The undue stress on creative products, previously uncovered by Laske's (1989) research, was further questioned through an increased focus on creative potentials (Keller 1999a; Keller 2001; Keller and Capasso 2000). Three interrelated concepts have boosted the notion that part of the aesthetic decisions could be left in the hands of the audience:

1. structural coupling: the close relationships among resources and creative agents;

2. pattern formation: the dynamic space-time distribution of creative by-products which could be fed back into the creative process; and

3. emergent properties: the materializations of the pattern formation processes as aesthetic experiences.

In 2001, after discussing the implications of the application of ecological models in creative practice, Keller synthesized those findings in these words: "[The ecological] perspective places the concepts of potentiality and actuality in musical meaning within the broader context of mutual determination between the individual and the environment. In this context, the interaction between the individual's specific sonic experiences and the music's structural processes establish a form-creation [dynamic] that brings forth an ever-changing history of meanings." (Keller 2001: 10).

Computational applications have been at the center of ecocompositional practices since the initial proposals in 1997. Two early works ... soretes de punta (Keller 1998) and touch'n'go / toco y me voy (Keller 1999b) demonstrated that ecological modelling could serve as a support methodology for creative musical activity (Keller 1999a; Keller and Truax 1998). These works featured the notion that emergent properties could be elicited through interactions among agents and objects within ecological niches. The adoption of a strict Gibsonian perspective implied a strong emphasis on the multimodal event as a working unit for creative practice. Later artistic projects - The trade / Oro por baratijas, The urban 
corridor / Corredor urbano (Capasso et al. 2000), Ukiuq Tulugaq (The Winter Raven) (Burtner 2005) - unveiled the need to extend the ecological approach to account for higher temporal levels. This trend was expressed in the following terms:

\begin{abstract}
Eco-composition emphasizes the relationships between the compositional processes and the geographical, [ethnological] and historical factors that inform the piece. From this perspective, the creative context becomes an integral part of the w ork. Furthermore, this dialogic relationship betw een extra-musical sources and compositional methods sometimes creates acute contradictions within the piece, steering the compositional process tow ard new directions. (Keller and Capasso 2006, p. 58).
\end{abstract}

During the first decade of the twenty-first century, several composers started a search for methods to handle action-perception cycles within their compositional practice. Barrett (2000), Opie and Brown (2006) and Harris (2009) developed data-extraction techniques that provided tools to deal with the complexity of the local sonic resources for musical purposes. Burtner (2005) explored the usage of synthesis techniques in external settings, coining the concept of socio-synthesis. Di Scipio (2008) employed the venue's acoustical properties to increase the available resources for performance-based compositional systems. Nance (2007) proposed the use of aural scores as a way to increase the openness of instrumental works. Cádiz (2012) employed ecologically based synthesis methods in the context of orchestral works. And Basanta (2010) and the Capasso+Keller+Tinajero Collective (2000; 2004; 2012; 2013 ; 2014) made use of ecologically based interaction techniques to enhance the creative participatory potential of their installation artworks. All these initiatives have contributed to the methods presently gathered under the rubric ecologically grounded creative practice (Keller and Lazzarini 2017).

\title{
5 - The perception-analysis-resynthesis model
}

Mannis's (2014) model applies the notion of sonic analysis-synthesis (Luce 1963) to the realm of creative practice. This three-stage model is structured as a directed cyclic sequence. The cycle starts with perception. After the extraction of (sonic) information, the operations of association, comparison and classification are applied. This leads to the second stage, analysis. Known musical models, structures and taxonomies are employed to provide the basis for a hypothesisconstruction process. Three broad strategies are available: regressive (or subtractive), expansive (or additive) and detouring. Alternatively, Mannis mentions the traditional approaches to problem solving: deduction, induction and abduction. The embedded aspect of the proposal is explicit in the mimetic 
procedures applied during the resynthesis stage. Through a process of assimilation (knowledge incorporation or renewed understanding), a continuum between realistic sonic representation and fiction is constructed. This stage feeds back into the perception stage, providing the basis for the next creative iteration.

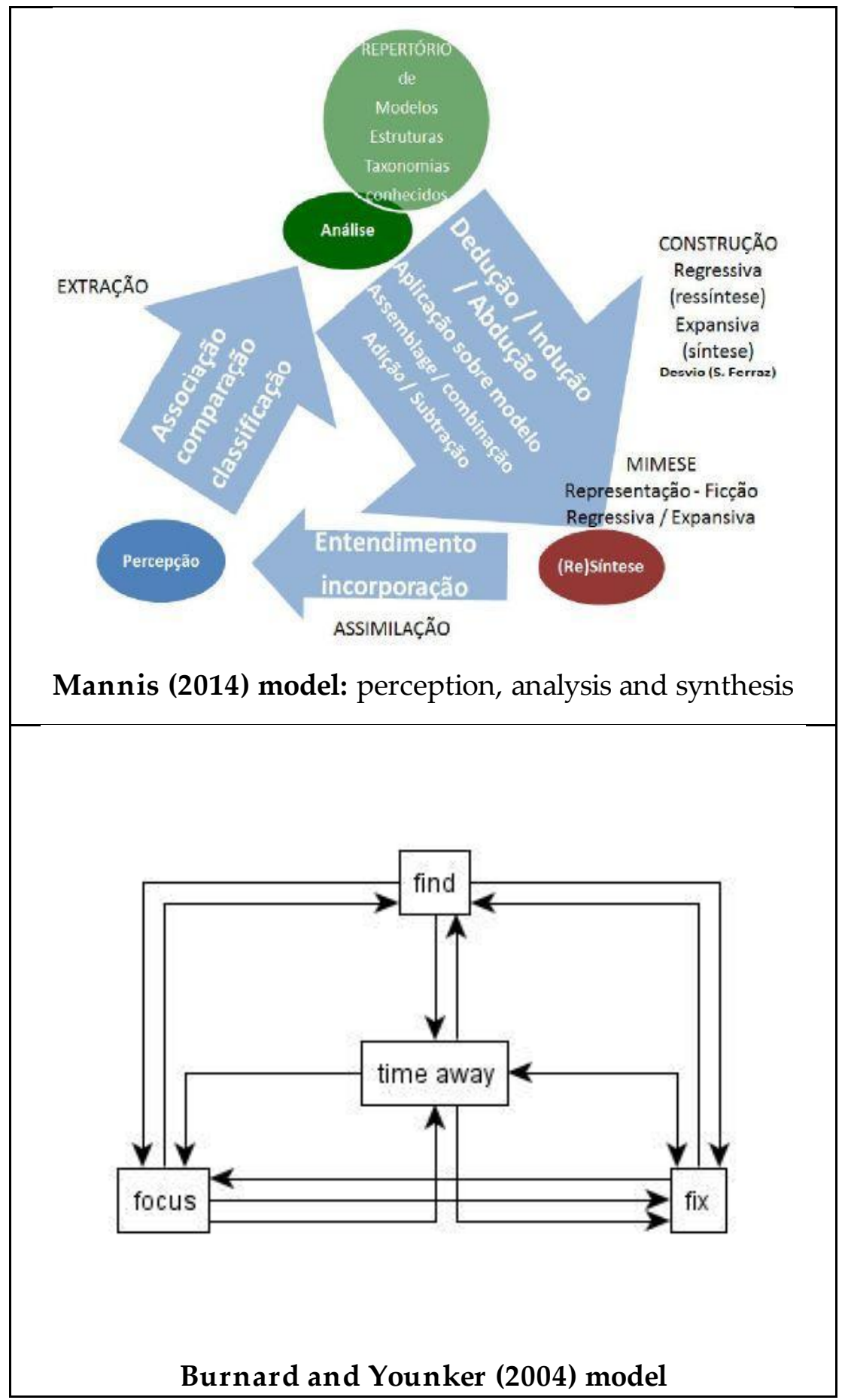

Figure 1: Comparing Mannis's (2014) perception-analysis-resynthesis model with Younker's and Burnard's (2004) iterative model 
Mannis's model (MM) is closely aligned with Burnard and Younker (2004) iterative model - BYM (see Keller et al. 2014 for a review). The perception stage provides an expanded version of the find stage in BYM. Both models refer to the resource foraging activity that is usually described as a precompositional generative stage. The analysis stage has a close resemblance to the fix stage in BYM, involving the selection and classification of resources to provide a viable setting for decision making. Finally, the resynthesis stage involves the subtractive processes implicit in the focus stage of the BYM. Nevertheless, MM's depiction of the creative cycle differs in two key aspects with the BYM structure. Firstly, the edges are directional, that is, the stages follow a fixed sequence: perceptionanalysis-resynthesis. BYM's structure is non-directional, any stage can follow or precede any other stage. Furthermore, BYM includes Wallas's (1926) incubation stage, described as time away.

Mannis's model partially addresses the concerns expressed by Keller et al. (2011). The importance of mimesis as a mechanism for creative activity has recently been underlined by the development of support infrastructure for ubiquitous musical activities. Both social interactions and interactions with the environment seem to shape the affordances for creative action (Keller et al. 2010). Thus, mimesis can be applied to two information-foraging strategies: interactions through social affordances and interactions through material (or natural) affordances. MM incorporates the three operations proposed by (Keller 2012): expand, constrain and shift. The shift operation (labeled detouring in MM) targets the mechanisms that fall outside the classic problem-solving approach (Newell et al. 1958). This operation produces material, behavioral or cognitive resources that were not available before the start of the creative activity. A key feature of the embedded-embodied approaches to cognition is a tight feedback between perception and action (Gibson 1979). Thus, the strongest link of MM to ecologically grounded paradigms is the emergence of resources during the exploratory activity, rather than through the application of disembodied analytical or problem-solving strategies. Nevertheless, some aspects of the model may not be amenable to ecologically grounded creative practice.

This model is likely to lead to successful results only if fostered by a supportive environment. Emmerson (1986) argues that an analysis - synthesis configuration, such as the one proposed by MM, would work fairly well in some realms of human activity (e.g. the natural sciences), but less clearly so in artistic endeavors. This is to do with the fact that the output of the analysis (explanation) is not univocal to the synthesis (prediction) element. Exploratory activities demand multiple instances of the synthesis stage to attain satisfactory directions. The lack of directionality and causality of the artistic activity puts a question mark on the applicability of the analysis-synthesis relationship. Only within a context that "encourages criticism and serious reconsideration of principles" 
(Emmerson 1986), the loop from synthesis to analysis and back to re-synthesis has a reasonable chance of working. A corollary of this argument is that we cannot adopt analysis uncritically as a foundation for systems, theories or methods of artistic creation, but possibly only as a good means of learning about them. As Emmerson suggests - rather than propose analysis-synthesis as a full explanatory framework - we should view it as a "process of understanding, refining, and perhaps assisting decisions based on perceptual criteria" (Emmerson 1986, p. 22).

Some of the limitations of the creativity models discussed in (Keller et al. 2011) are also relevant to the perception-analysis-resynthesis model. Recent advances in ecological cognition underline the importance of social interactions as a stabilizing mechanism for shared knowledge (Hutchins 2010). For instance, the concept of audience - recently proposed as a key creativity factor by Glăveanu (2013) - stresses the fact that all creative activities rely upon social exchanges. The social dimension has been explicitly addressed in ecologically grounded creative practices since 2000 (Keller and Capasso 2000). Therefore, both the theoretical approaches and the creative practice point to the need to include social interaction as a key element of ecologically grounded models of musical creativity (see discussion on behavioral ecologies below).

Another creativity factor that seems to be absent in MM is place (Rhodes 1961). Despite the push toward the incorporation of mimesis, MM seems to adopt a narrow approach to embodiment. Rather than establishing a rapport between environmental features and aesthetic decisions (Keller 2000; Truax 2002), MM's interpretation of mimesis seems to be limited to the imitation of animal behaviors. Undoubtedly this is an important class of phenomena, but it is not the only type of information that impacts creative activity. Recent ubimus research indicates that the material resources - i.e., objects and sonic cues - may also shape the actions of the agents through the use of constraints provided by the local environment to assist in the aesthetic decision processes (Keller et al. 2013).

\section{6 - Distributed agency: behavioral ecologies}

Jones et al. (2012) suggest that individual compositional activities can be modeled through two stages: generation and evaluation (henceforth the generation-evaluation model). Following McGraw's and Hofstadter's (1993) proposal, generation encompasses both foraging activities and the internal processes that lead to new ideas. Evaluation involves processes of selection of the available resources. These two activities are carried out through three operations: amplify, when the pool of resources gets larger; constrain, when the pool of 
resources gets smaller; and no operation, when the resources are unmodified. A fourth operation, involving a radical change of perspective, is labelled impose.

The generation-evaluation model gives support to the ecologically grounded view on musical creativity as laid out by Keller (2012). Based on the procedural analysis of five representative works of the late twentieth century, Keller (2012) suggests that sonic ecologies involve interactions among human agents and material resources. These interactions can be described by three operations on the material resources: expand, when the pool of resources gets larger; constrain, when the pool of resources gets smaller; and shift, when a qualitative change of resources is involved.

Jones and coauthors (2012) usage of the nil operator - suggested by the lack of change in the resource pool - is consistent with the incubation stage proposed by Wallas (1926). The lack of activity has been incorporated by the majority of recent musical creativity models (cf. reviews in Keller et al. 2014). It is usually described as time spent away from any focused activity. Given the recent findings on the function of the default mental network - i.e. the neural pathways stay active despite the lack of conscious processes usually linked to the area of the prefrontal cortex - it is very likely that activities that have no impact on the material resources, such as sleeping or doing repetitive physical activity, provide an opportunity for reconfiguring the cognitive resources devoted to the creative act. Hence, a more accurate description of the nil operator is the lack of explicit or conscious processes, enhancing the role of the implicit cognitive resources.

Despite Jones's and coauthors' acknowledgement of the distributed nature of the creative act, the generation-evaluation model does not account for phenomena involving the active participation of distributed agents and resources. There are two aspects to be considered. On one hand, as multiple studies have shown since the early ecologically grounded proposals (Burtner 2005; Keller 1999; 2000; Keller and Capasso 2006), musical creative activities are embedded. That is, they do not depend only on the cognitive resources of the participants. Eco-grounded musical activities feature emergent properties arising from interactions among human agents and material resources, namely affordances. These are defined as opportunities for action provided by the features of the environment as perceived by the active agent (Gibson 1977). As discussed in (Keller et al 2010), authors in the area of HCI - for instance in (Norman 1988/2013) - have misused this concept fairly regularly in the past, making it problematic. It is possible to sidestep these issues by proposing a more neutral terminology, relational properties, to denominate the design qualities that emerge from interaction (Keller et al. 2015b, 2015c). Behaviours change materials and materials change behaviours fostering processes of affordance formation. These processes impact the way the resources are employed to support creative activities, yielding dynamic relationships among resources and agents, or 
relational properties (Keller et al. 2014, 2015a, 2015b). Three types of relational properties have been identified: material, social and formal. The first type arises in interactions with physical objects, while the second emerges from interactions among agents. Formal relational properties are instantiated through cognitive simulations, as well as through conceptual operations - involving offline cognitive resources (Wilson 2002). Furthermore, there is a decoupling of the formal types from agent-object and agent-agent synchronous interactions.

Complementarily, musical creative activities are social. This means that the material resources are not limited by the experiential knowledge of a single creator - knowledge is accumulated and distributed among all the agents participating in the creative act-sometimes conforming a community of practice (Wenger 2010). The social aspects of creativity highlight the need to consider the distributed nature of the agents involved in the creative act. The romanticized depiction of the genius-composer working in his studio -isolated from the hustle of mundane distractions - is currently being challenged by ubiquitous musical practices (Keller et al. 2014). The situated methods that have emerged from ecologically grounded creative practices fit well within the context of community-oriented ubimus research (Lima et al. 2012; Pimenta et al. 2014). While the generation-evaluation model was developed keeping in mind a single participant, ecologically grounded practices have targeted the integration of the audience as an active shaper of the artistic experience (Basanta 2010; Burtner 2011; Keller and Capasso 2006). The dismissal of the composer as an endless fountain of creative knowledge calls for a revised view on agency to account for the socially distributed factors involved in community-based creative phenomena.

A notion that has emerged within the context of ecologically oriented music research - the behavioral ecology - has served to question the idea that artistic decision-making depends solely on the inspiration of an individual creator. Nance (2007, p. 20) suggests that "whereas the monitor-computer-composer interaction is generally an analysis / re-synthesis [activity] that occurs at a duration between seconds and maybe days, the written analysis-composition [cycle] is occurring over a period of weeks and maybe years. it could, in fact, continue far beyond the composer's own research to be continued indefinitely." This temporal level proposed by Nance - more properly defined as social interaction (Keller and Capasso 2006) - points to the need to consider the agents' behaviors as components of a larger system of relationships encompassing not only aesthetically oriented experiences but also everyday activities that impact creative actions. The dynamic depiction of relational properties proposed by Keller et al. (2015) together with the snapshot depiction of the structural resources laid out by Di Scipio (2014) back the concept of behavioral ecologies as units of study of ubiquitous musical phenomena. Behavioral ecologies both 
require and produce human behaviors. When placed within the context of creative practice, behavioral ecologies may target the deployment of resources for creative action. Some ecologies exhibit creative behaviors as by-products of the interactions among agents and material resources. These by-products can become resources for future actions, they can be experienced as creative products or they can be discarded as creative waste (see section on In-group, Out-group model). Creative by-products can be employed to assess the sustainability of a creative ecology.

It has been suggested that installation art is an ideal venue for the experimentation of social factors that underlie group behaviors (Emmerson 2001). In this environment, visual, sonic, and tactile cues produced by the agents' actions compose the ranges of interactions that impact the behavioral resources. An important class of material resources for creative musical activity is the available technological infrastructure, or the ecosystem of technological resources. This infrastructure both constrains and affords creative activity. Hence, behavioral ecologies for music making encompass tools, behaviors and resources that afford and constrain human creative actions.

\section{7 - The In-group, Out-group Model (MDF)}

The recent literature on creativity (Kozbelt et al. 2010) describes the result of the creative activity as a 'product'. We believe that when dealing with ubiquitous musical activities this differentiation is only possible a posteriori. Depending on how the materials are used, the labels resources or products may be applied. During the generation of creative products, renewable resources can be used repeatedly. For example, synthesis models that produce new sonic results for each iteration (see ecological models, Keller and Truax 1998) yield both relevant - in this case consistent with the sound class defined in the model - and original materials, i.e., the generated sounds are not literal repetitions of previous instances. Techniques based on repetitive recycling - such as looping - lose originality after the initial iteration. Therefore, they depend on the constant incorporation of new material resources (see Daisyphone, Bryan-Kinns 2004). The computational models of data generation (ecological modeling in the first case and looping in the second case) are part of the material resources used during the creative activity. The sounds generated through interactions with the computational system - exerted by the actions of the agents (composers or system users) - form part of the creative output. However, the material generated during the creative activity can only be characterized as a creative product if it is relevant to the stakeholders. In other words, for a material resource to become a creative product, the agent needs to characterize the resource as both relevant and 
original. Otherwise, the product becomes part of what might be called creative garbage or waste. In short, ubiquitous musical systems can be described as systems of activities that utilize and generate material resources. Material factors are characterized by the stakeholders as either creative resources or products. If the outcome meets the criteria of originality and relevance it is considered a product, otherwise it is discarded, constituting creative waste.

To identify factors related to the production of creative waste, Ferraz and Keller (2014) separate human factors and material factors. From an ecological perspective (Keller 2000; Keller and Capasso 2006), the material aspects are related to the interactions with objects, and the human aspects entail interactions with other agents. These two forms of interaction impact the set of forces that shape collective creation, pushing the musical systems to homogeneous states (when agglutination forces prevail) or to heterogeneous states (when the tendency to disaggregation is imposed). In relation to the production of creative garbage, the forces of agglutination (in-group) and disaggregation (out-group) can be exemplified by comparing a child with an experienced musician doing an improvisation. The child generates a lot of original material, but most of this material is irrelevant. The chances of a musician generating original material are low, but the material is usually relevant. The same concept can be applied to groups of participants in creative activities. A group of novices generates a lot of junk. Gradually, as the choices are honed, the quantity of irrelevant material is reduced. Eventually, after a long period of joint work, the group reaches a level of proficiency in which most of the material generated is relevant. At this point the agglutination (in-group) forces predominate, hence the creative products of the group have reduced levels of originality as compared to the previous states. Concomitantly, consensus among the participants is easily reached. To reach this type scenario, it should be emphasized that collective creative manifestations usually demand long learning periods.

Continuing with the metaphor of the lay group and the professional group, experienced musicians have access to large amounts of material resources (greater knowledge) but their actions generate a lot of creative garbage due to their high selectivity (implying greater consensus and greater consistency). Contrastingly, lay participants produce large amounts of original material of little relevance due to their lack of experience with the material resources (less knowledge) or due to easily reached common sense (as opposed to well-informed consensus). Sticking to the notion that those who participate in the creative activity are the ones who choose the materials, novices have limited interaction with the resources hence the likelihood of achieving consistent results is fairly low. When consensus is reached, the relevance of the results is also low, increasing the odds of producing garbage. At the same time, the easily attained consensus (motivated by their low selectivity, related to the small amount of 
interaction with the other members of the group) reduces the production of waste. Professional musicians are highly selective (due to their higher level of consensus, related to the longer periods of group interactions), therefore the output of waste is usually larger. Concomitantly, their knowledge of the material resources increases the likelihood of producing relevant and consistent results, thus reducing the potential amount of waste.

In short, the production of creative waste can be linked to two variables: the extant knowledge of the material resources and the consensus among the stakeholders. In ubiquitous musical systems where in-group forces predominate, high knowledge levels tend to reduce the quantity of garbage, while high consensus levels have the opposite effect - they yield more garbage through the disposal of irrelevant material. In ubiquitous musical systems where out-group forces prevail, the participants' lack knowledge of the material resources leads to increased garbage production. But at the same time the high tendency to reach a consensus - due to the group's low selectivity, described as common sense - tends to reduce the garbage production.

So far, we have discussed current music-theoretical models that target creative manifestations. These perspectives were placed within the context of state-of-the-art creativity theory. The impact of technology on creative practices has fostered a new avenue of research - ubiquitous music (Keller et al. 2014a). The ubimus perspective may provide viable strategies to deal with issues that fall outside the realm of previous music-theoretical approaches. One aspect highlighted by this discussion entails the assessment of the models' predictive power involving deployments and observations of key creative factors. Another issue that has emerged through the theoretical analysis of the creativity models is whether these proposals can handle diverse music making practices. A particularly tricky methodological problem is how to deal with creative manifestations that are not restricted to instrumentally oriented forms of sonic organization and that do not abide by the rules of professional musicianship. The second part of the paper will highlight the methodological aspects of the ubimus perspective. We will focus on a small set of highly contrasting cases to give a sample of the issues involved while deploying support technologies for creative music making.

\section{PART 2}

\section{8 - Ubiquitous music: methodological contributions}

Ubiquitous music, as a construct defined from the ground up by a community of practitioners (Keller and Lazzarini 2017), proposes to study complex systems of human agents, material resources, their affordances with 
regards to musical activities supported by a variety of tools (Keller et al. 2014a). As a human-centric area, ubimus stresses the importance of considering the factors involved in hominid evolution, observing the current perspectives of evolution theory that have significant implications in creative practice. Two approaches in this area are worthy of mention: the social brain hypothesis (Dunbar and Schultz 2007) and the niche construction theory (Odling-Smee et al. 2003). The importance of social interaction mechanisms for survival is shown by the first of these two perspectives, as, for instance, prediction of intention is put forward as a key component leading to the development of higher cognitive ability. Somewhat complementary, the second approach explores the local impact on the environment, with the emergence of ecological niches, and its shaping of an increasingly refined cognition mechanism arisen as a response to uncertain conditions.

Material resources, as elements within the ubimus sphere, form a significant aspect of creative projects and serve to constrain the behaviors of agents, while generating or organising other material resources. Creative heuristics, based on sonic behavior in given settings (Keller 1999; Keller 2000) are put forward by ecological modelling processes in sound synthesis (Keller and Truax 1998; Keller and Berger 2001), instrumental composition (Burtner 2005; Nance 2007), interaction design (Keller et al. 2002; Keller et al. 2010), and environmental data extraction and sonification for artistic purposes (Gomes et al. 2014; Opie and Brown 2006). These approaches make use of local resources as an open means of sonic organization. It is possible to observe in them the emergent qualities of behavioral patterns across modalities. These can at times explore contradictions and paradoxes through the expansion of the sonic properties of real-world events. Such systems that make use of environmental features can be characterized as multimodal ecologies in ubimus.

The creative tools (technological or otherwise) studied in ubimus can be seen as forming a class of ecosystems, the ubimus ecosystems. This proposal stresses the central role of creativity as a central target for tooling support. Research in HCI-related aspects of creativity has been pioneered by Edmonds and Fischer. Information Technology Creative Practices have recently added weight to this perspective, indicating that the development of creativity support tools can provide a renewed focus in HCI research (Mitchell et al. 2003; Shneiderman 2007). Ubimus ecosystems function as technological hubs that support the integration of audio and interaction tools. These ecosystems can be reconfigured according to the needs of the users through rapid prototyping techniques. This avenue of research emphasizes the interrelated character of ubiquitous musical interactions featuring support both for audio processing and for rapid user interface prototyping. For instance, Lazzarini et al. (2014a) report the development $\mathrm{PNaCl}$ Csound. The $\mathrm{PNaCl}$ Csound environment can be used 
to develop of a variety of ubimus applications on standard internet browsers. It is based on an open-source, domain-specific language featuring a wide-ranging variety of unit generators (over 1,500 Csound opcodes). Thus, while it supports the prototyping of reasonably complex audio processing applications, it can also benefit from a large library of code from the various pre-existing catalogs of Csound algorithms. The Csound $\mathrm{PNaCl}$ environment features a relatively lowlatency performance and incorporates thirty years of Csound know-how, fostering the development of ubiquitous music ecosystems based on standard web browser technology. On the down side, application support is not universal, as it is the case in all browser-based software development systems. Furthermore, the current pace of renovation and the variety of browser technology place a high demand on maintenance. New features are quickly incorporated and some functionalities become obsolete.

An approach that places tools as central concepts of a research program me might not be entirely successful in some cases. The usage of isolated tools might depend on the existence of well-defined problems, in situations where the target of the procedure is defined before the start of the activity (Fantauzzacoffin and Rogers 2013), thus the tool choice and design may not help to define the epistemic target. In most artistic endeavors, however, there is a mixture of both undefined and clearly defined problems, which may also put into question established worldviews (Donald 2006). Artistic work is therefore within the realm of selfreflective activities (Hamman 2002; Donald 2006), where the objectives are established during the act rather than a priori. This situation demands a more fluid strategy than that provided by a teleological approach that favors the early definition of a target.

A key challenge in ubimus research is the provision of intuitive tools for diverse creative tasks. Ubimus systems should ideally support the users' creative potential by fostering easy access to material and social resources. Depending on the approach, the development of certain technologies may have the unwanted side-effect of restricting the support to a small user base. This is often the case in the area of new music instruments. For example, while the provision of custommade, special purpose hardware interfaces, as proposed by the tangible user interface design approaches (Fitzmaurice et al. 1995; Ishii et al. 2001) can fulfil the requirements of transparency and naturalness reducing the cognitive load of complex tasks, they do not guarantee a wide-ranging adoption by a large cohort of users (often due to financial, as well as distribution and maintenance constraints). Ubimus attempts to solve this issue by focusing on repurposing, which entails the use of existing, everyday technology, for creative ends: personal mobile devices (Flores et al. 2010, Lazzarini et al. 2012), web technologies (Lazzarini et al. 2015b), and DIY hardware (Lazzarini et al 2015c). While these approaches have proved successful, ubimus still faces challenges regarding the 
sustainability of its technological infrastructure. Therefore, ubimus concepts are validated through the development and deployment of specific technologies but can also handle changes in the underlying platforms and toolsets. The next section features four examples of the fluid relationships between conceptual approaches and actual deployments nourished by ubimus methodologies. Through rapid prototyping and lightweight knowledge-sharing methods, ubimus research strives to meet the creative needs of a wide variety of stakeholders in settings that were previously considered unworthy for artistic intervention.

\section{9 - The Internet of Musical Things: a new ubimus frontier}

The emergence of a new connectedness via small networked computing devices, known as the Internet of Things (IoT) (Huang and Li 2010; Ulckerman et al 2011) has opened up a new frontier for ubimus research. The term was coined by Kevin Ashton (van Kranenburg and Bassi 2012) to describe the integration of a multitude of devices where the effective separation between computer and peripheral is erased. The prediction is that the number of connected components will far outnumber the current size of the internet. Devices and computation will be integrated into a world where there is a seamless transition between a virtual and a real environment (Uckelmann et al. 2011). While much of the research in IoT seems to be directed to its business potential, the particular definition of IoT as an interface between the material everyday world and a constructed, abstract, but at the same time real and connected, computing universe has a significant potential for ubimus interventions.

The development of the Maker Movement (Dougherty 2012) and the doit-yourself (DIY) mode of operation have provided the means for the development of a whole new ubimus ecosystem alongside the more established off-the-shelf hardware-based manifestations. While these have provided the main vehicle for ubimus activity (Flores et al. 2010; McGlynn et al. 2012; van Troyer 2014) with a considerable amount of repurposing, we now have to ponder how custom DIY hardware might impact research in this area. Seizing upon these opportunities, we can see the development of an Internet of Musical Things (IoMusT) $)^{2}$, built primarily on customized devices with full network integration. This opens up some new possibilities based on affordability, connectivity, remote

\footnotetext{
2 Current efforts in ubimus research point to an emerging field that brings together the Internet of Things infrastructure with the methods and concepts laid out in ubimus. There is no established label yet. IoMT, IoMUT (Turchet et al. 2017), IoMuT and IoMusT are possible signatures and keyw ords.
} 
control, data gathering capabilities (sensing), and interaction with people and objects over potentially large geographical areas.

Such a massive and heterogeneous platform poses new opportunities as well as new challenges. The question of energy usage and conservation is one that will demand some attention as pointed out by (van Kranenburg and Bassi 2012), in addition to the increase of material waste. A solution could involve zeroentropy, self-sufficient, devices as design targets. Further ethical issues would also be of relevance such as privacy and use of data (which are also encountered in other ubimus environments). Engagement with these issues is by no means an established practice in systems design (Spielkermann 2011), but it should be a sine-qua-non consideration for ubimus and IoMusT.

An early example of the ubimus possibilities of IoMusT was demonstrated by the Memory Tree project (Ribeiro Netto et al. 2015). Its implementation was based on equipping a tree at a university campus with the capabilities of holding sonic and musical memories that would allow users to interact both locally and remotely via the internet. This involved the design of purpose-specific DIY hardware, alongside a significant amount of repurposing. It employed a widely used mobile-phone messaging application and caught a ride on the ubiquitous internet infrastructure. The fundamental shift here is that the installation explodes the boundaries of the real/material world and its virtual counterpart, seamlessly providing interactions that allow both local and remote participation. Such interventions are on the cusp of something that may enable a qualitative leap in ecologically grounded creative practices.

\section{PART 3:}

\section{0 - Case studies in ubimus}

The next sections tackle the application of the ubimus approach to the study of four contrasting creative musical situations. The first case encompasses a set of experiments targeting casual participants doing creative activities in domestic, transitional and outdoor settings. The second case involves both musicians and by-passers (with no musical training) in improvisatory sessions. A special feature of this study is the location chosen: an audio and musical equipment store. The third case is a longitudinal study of the design process of a multimodal installation. This is among the first projects to focus on the procedural aspects of creative decision-making in music. 
KELLER, Damián; LAZZARINI, Victor. 2017. Theoretical Approaches to Musical Creativity: The Ubimus Perspective. MUSICA THEORICA. Salvador: TeMA, 201701, p. 1-53.

\begin{tabular}{|c|l|l|l|l|l|l|}
\hline case & target & subjects & $\begin{array}{c}\text { support } \\
\text { strategy }\end{array}$ & $\begin{array}{c}\text { musical } \\
\text { activities }\end{array}$ & highlights & limitations \\
\hline 1 & little-c & $\begin{array}{l}\text { novices } \\
\text { or casual } \\
\text { participants }\end{array}$ & $\begin{array}{l}\text { time } \\
\text { tagging }\end{array}$ & audio mixing & $\begin{array}{l}\text { effective } \\
\text { support at } \\
\text { everyday } \\
\text { settings }\end{array}$ & $\begin{array}{l}\text { small } \\
\text { quantity of } \\
\text { sonic } \\
\text { resources }\end{array}$ \\
\hline 2 & $\begin{array}{l}\text { mixed } \\
\text { creativity } \\
\text { magnitudes }\end{array}$ & $\begin{array}{l}\text { musicians } \\
\text { and casual } \\
\text { participants }\end{array}$ & $\begin{array}{l}\text { stripe } \\
\text { metaphor }\end{array}$ & $\begin{array}{l}\text { improvisatory } \\
\text { sessions }\end{array}$ & $\begin{array}{l}\text { high level of } \\
\text { engagement }\end{array}$ & $\begin{array}{l}\text { difficult } \\
\text { deployment } \\
\text { or } \\
\text { awkward } \\
\text { knowledge } \\
\text { transfer }\end{array}$ \\
\hline 3 & $\begin{array}{l}\text { behavioral } \\
\text { ecologies }\end{array}$ & artists & $\begin{array}{l}\text { creative } \\
\text { surrogates }\end{array}$ & $\begin{array}{l}\text { multimodal } \\
\text { design }\end{array}$ & $\begin{array}{l}\text { contrasting } \\
\text { profile of } \\
\text { social and } \\
\text { material } \\
\text { interactions }\end{array}$ & $\begin{array}{l}\text { small } \\
\text { number of } \\
\text { empirical } \\
\text { studies }\end{array}$ \\
\hline
\end{tabular}

Table 4: Profile of the case studies

\section{Case 1: Supporting little-c musical creativity through time tagging}

Keller and collaborators (2010) proposed timetagging as a strategy to avoid the computational burden of the visually oriented approaches to audio mixing. This creativity support metaphor provided a fertile ground for musical experiences in everyday environments engaging both musicians and nonmusicians (Farias et al. 2014; Pinheiro da Silva et al. 2013). Experiments with naive users doing simple mixing activities on portable devices indicated that the time tagging metaphor ensued more effective support than the traditional tapeediting metaphor featured in most desktop audio editing software (Farias et al. 2014; Radanovitsck et al. 2011).

Two generations of prototypes were designed and deployed. After completing an initial validation phase involving expert usage (see Green Canopy On The Road ${ }^{3}$ - Keller et al. 2009), two experimental studies focused on the demands of naive participants in everyday settings. An initial study (Pinheiro da Silva et al. 2013) comprised creative activities in public settings - at a shopping mall, at a busy street and in a quiet area featuring biophonic ${ }^{4}$ sounds - and in private settings - at the home of each participant and at a studio facility. Six subjects participated in 47 mixing sessions using samples collected at two outdoors sites comprising urban sounds and biophonic sources. Creativity

\footnotetext{
3 This is the first documented ubimus artw ork. It w as premiered at the Brazilian Symposium on Computer Music, held in Recife, PE, in 2009.

4 Sounds produced by non-human animals.
} 
support was evaluated by means of a creative-experience protocol encompassing six factors: productivity, expressiveness, explorability, enjoyment, concentration, and collaboration (CSI-NAP v. 0.3 - Keller et al. 2011c). Outdoor sessions yielded higher scores in productivity, explorability, concentration and collaboration when compared to studio sessions. Compound effects of sound sample type and activity location were observed in the explorability factor when biophonic sound samples were used. Similar effects were detected on explorability, productivity and concentration in the conditions employing urban sounds.

A second study made use of recorded vocal samples created by the participants (Keller et al. 2013). To untangle the effects of place and activity type, three conditions were studied: place, including domestic and commercial settings; activity type, i.e. imitative mixes and original creations; and body posture, realizing the mix while standing or sitting. Ten subjects took part in an experiment encompassing 40 interaction sessions using mixDroid. Subjects created mixes and assessed their experiences through a modified version of the protocol applied in previous studies (Keller et al. 2011c). Explorability and collaboration factors yielded superior scores when the activities were carried out in domestic settings.

These results highlight the impact of the venue on the assessment of everyday creative experiences. The outdoor spaces were preferred by the participants of the first study. Domestic settings got slightly higher ratings in the second study. The profile of the subjects impacted the results of the second study but this trend was not confirmed by the first study's results.

Implications of Case 1: Since Richards and coauthors' (1988) pioneering study, everyday creativity has been researched by psychologists, designers and technologists. Despite these efforts, everyday musical activities (sonic manifestations of small creativity) have only recently been approached as a valid research topic. There are two perspectives that have targeted non-professional music making: ethnomusicology (Quiñones et al. 2013) and ubiquitous music (Keller et al. 2014a). Ubimus research is particularly relevant for everyday musical activities that demand the use of technology. Furthermore, given that almost all aspects of twenty-first century musical practice involve information technology - from concept-sharing and production to documentation and data collection - it can be argued that ubimus research will eventually become relevant to most manifestations of musical creativity.

\section{Case 2: Mixed creativity magnitudes in everyday settings}

The second generation of mixDroid prototypes incorporated a new interaction mechanism: the stripe (Figure 2). The stripe acts as a functional unit 
that features both interaction and audio manipulation. It isolates the functionality previously linked to the audio channel in analog systems, supporting synchronous interaction with a large number of elements to overcome the screensize limitations of small devices. Stripes enable mixing using both hands. The amount of active stripes depends on the device's computing power and on the participant's cognitive abilities. Thus, similarly to previous time-tagging implementations (see Case 1), devices with low computational resources can be used for complex creative activities in everyday contexts.

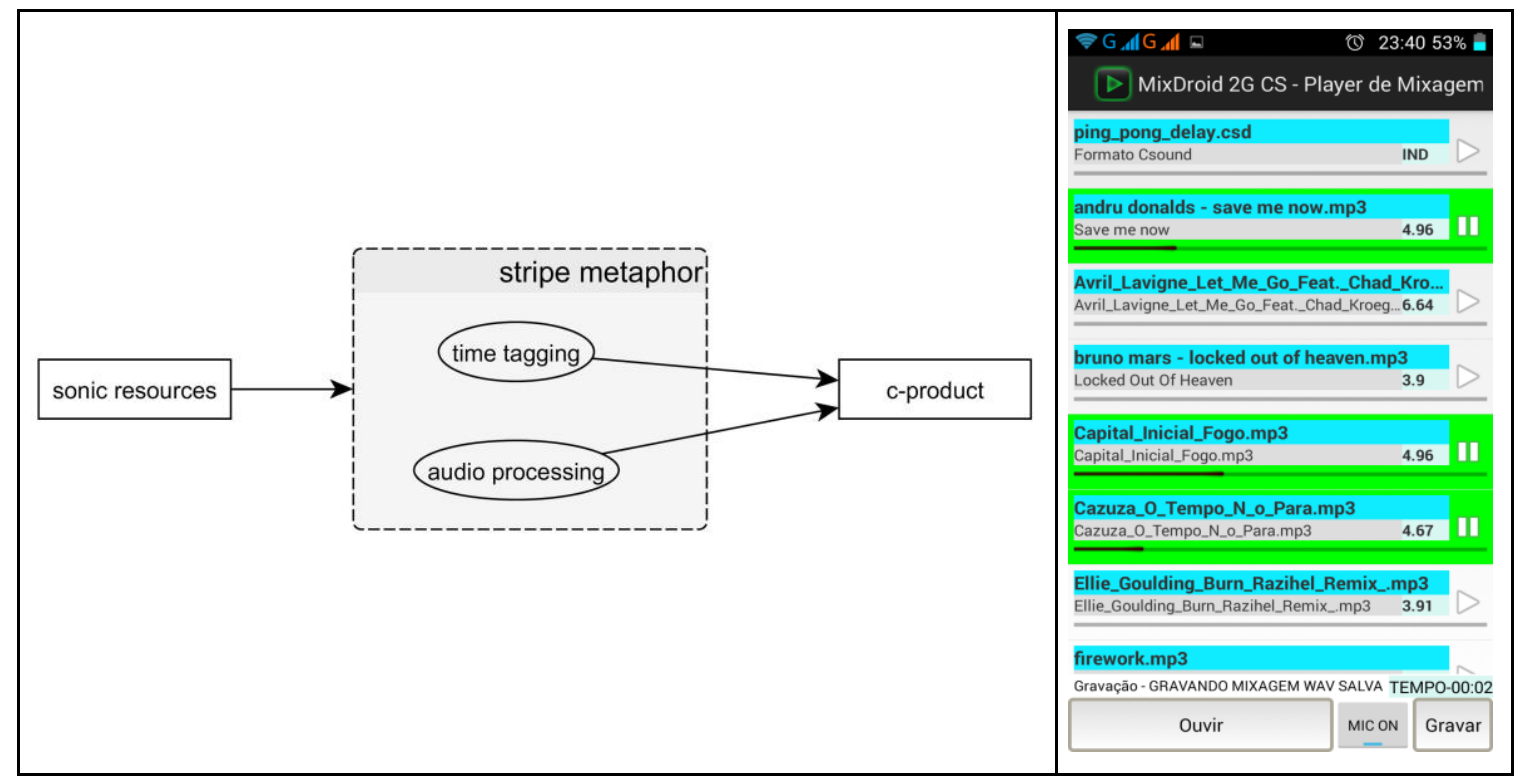

Figure 2: The stripe metaphor. By rolling the stripes up or down, multiple audio samples can be accessed on small portable devices

The second generation of mixDroid prototypes uses the stripe as an entry point to the sound data. Each stripe displays basic information on the sound sample being handled, including the file name, the total running time, the current time and the execution state (Farias et al. 2014; see Figure 2). Each sound file linked to a stripe is processed independently.

This study addresses the impact of the stripes creativity support metaphor in musical activities involving both musicians and novices. The Provocative Synthesis II study is based on the premise of action and reaction: a mixDroid player and musicians performing on traditional instruments alternate as instigators and respondents. This improvisational proposal features audio sequences triggered in mixDroid $2 \mathrm{G}$ by casual users.

Settings and equipment: The study was carried out at an audio and musical equipment store located in downtown Rio Branco, AC, Brazil. All the equipment was set on table at a visible location within the store. The hardware included a portable computer, a six-channel JamHub mixer, and stereo good-quality 
headphones for each of the participants. The prototype mixDroid $2 \mathrm{G}$ was used on an Iconia One Acer tablet, running the Android 4.1 operating system. The JamHub system (White 2010) features independent returns through headphones for each user. The output from the mixer was routed to the computer and sound levels were monitored by the researcher (Figure 3). The musicians played electric guitar and electric bass. They stood facing each other, making it possible to communicate through gestures.

Subjects profile: Twelve subjects participated in the sessions, including 6 musicians and 6 laypeople. Their average age was 28.5 years with a standard deviation of 6.76 years. Three of the six self-reported musicians had no formal study but boasted ten or more years of proficiency playing either electric bass or electric guitar.
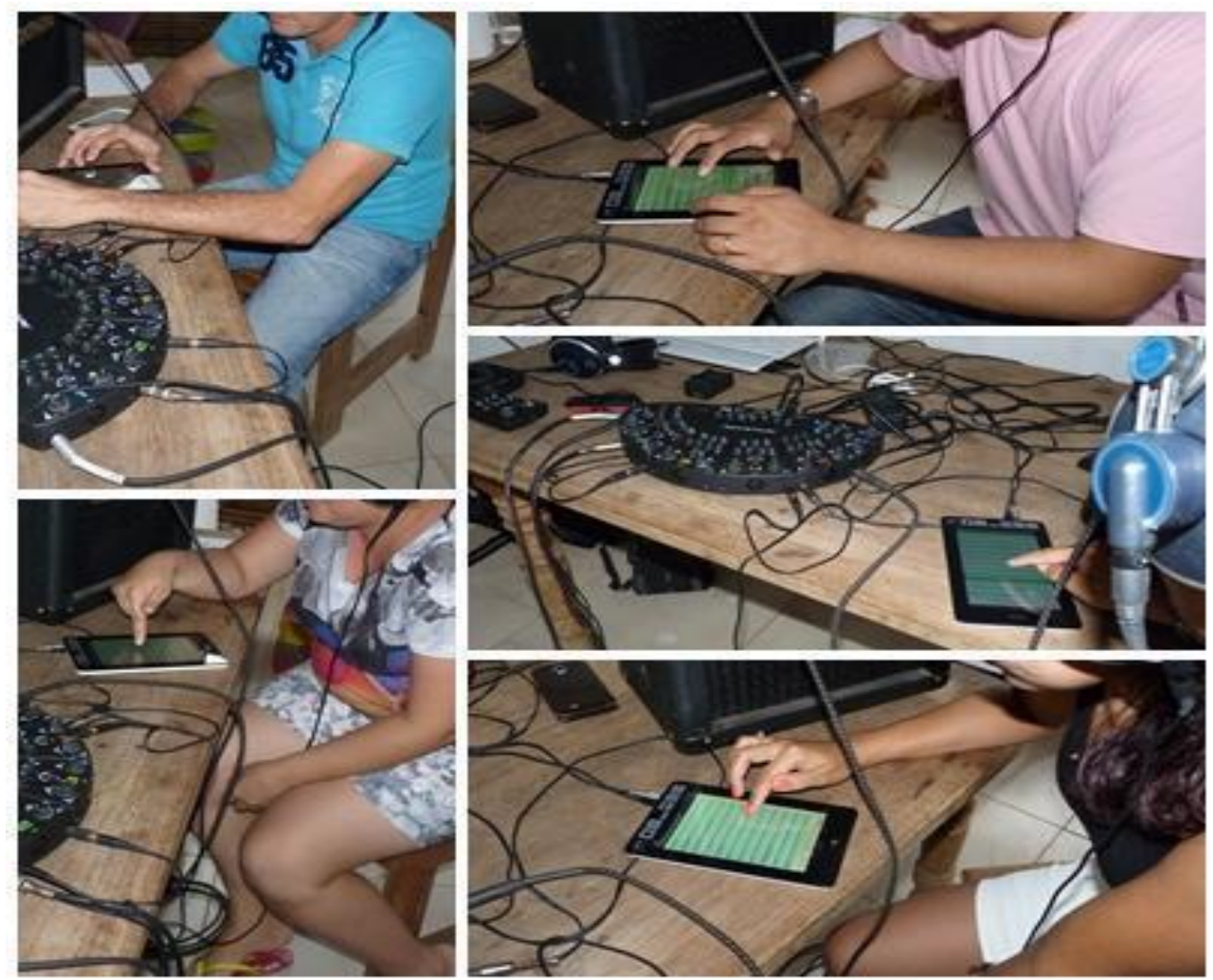

Figure 3: Subjects participating in Provocative Synthesis II at an audio and music equipment store.

Procedures: Eleven improvisational sessions were done by an average of 4 participants per session. The lay participants chose to sit on the benches while the musicians preferred to play standing. Each activity lasted approximately two minutes. Musicians were free to improvise within the bounds of a rhythmic reference laid out on a soundtrack. Throughout the sessions, the mixDroid player initiated the sonic exchanges. The sound products were recorded as

\section{MUSICA THEORICA}


uncompressed stereo PCM files and the final editing was done using a commercial DAW.

Data collection procedures: Data was collected through printed forms that were filled by all the participants immediately after each session. As in previous creativity assessment experiments (Farias et al. 2015; Lima et al. 2012; Pinheiro da Silva et al. 2013), we employed the CSI-NAP, an adapted version of the Creativity Support Index proposed by Carroll et al. (2009). Two factors assess the creative product (relevance and originality). The other four factors target the experience involving the settings, the tools and the participants' experience (easiness of use - the inverse of cognitive effort (Kahneman 1973; Sweller 1988); focus on activity; fun or enjoyment during the activity; productivity - whether the activity and the result were considered productive; and collaboration involving the support for social interaction among the participants). The 5-point Likert scale adopted varies from 'I strongly disagree' (-2) to 'I strongly agree' (+2). Zero stands for no preference or no answer.

Results: The overall results indicate a positive assessment of the experience (Figure 5). Strikingly, both musicians and non-musicians gave the highest rating to collaboration support $(2.00 \pm 0.00)$. Enjoyment was also highly rated with little variation among sessions $(1.91 \pm 0.30)$. Easiness of use got high ratings by all subjects except one $(1.73 \pm 0.90)$. The other two descriptors of the experience got positive ratings but higher standard deviations: focus $(1.64 \pm 0.50)$ and productivity $(1.55 \pm 0.69)$. Finally, the musical product was described as being creative, but this result was not uniform across subjects: relevance $(1.55 \pm 0.52)$ and originality $(1,64 \pm 0.50)$.

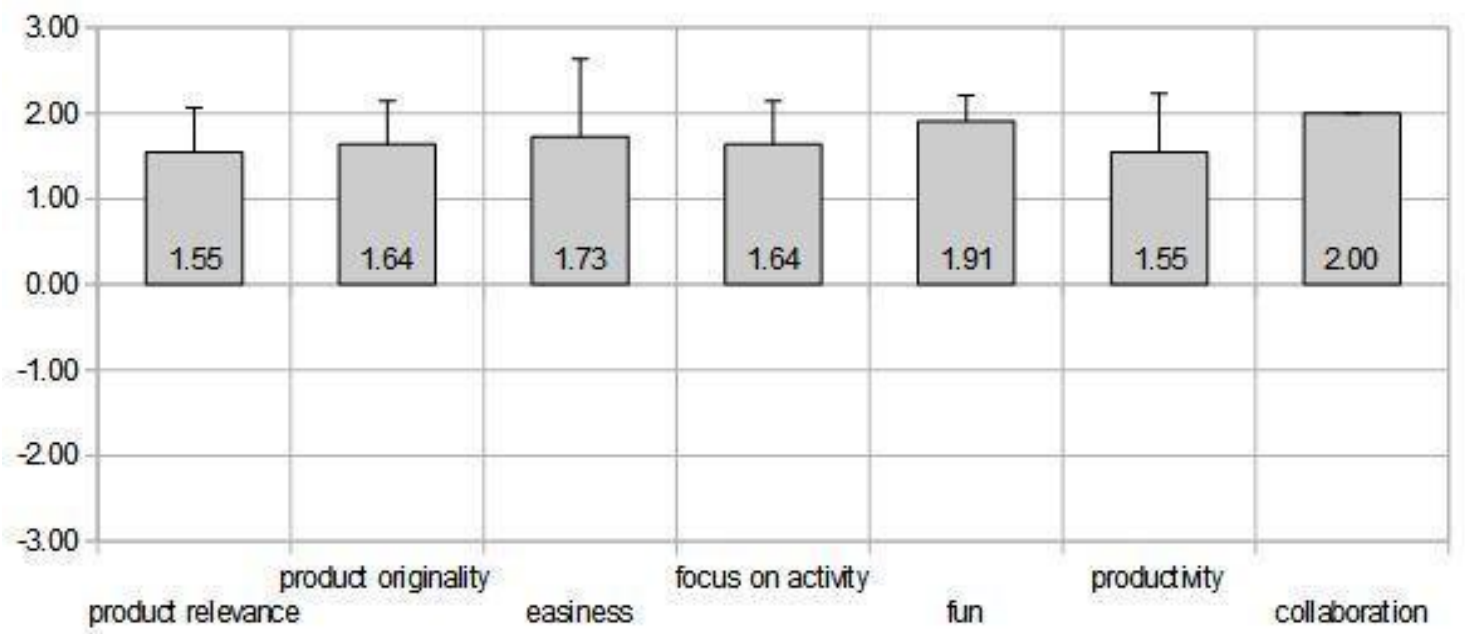

Figure 4: Results of the Provocative Synthesis II experiment for 11 iterations by 4 subjects per session. Data collected through the CSI-NAP 
In contrast with previous experiments in everyday musical creativity (Keller et al. 2013, 2015; Keller and Lima 2016; Pinheiro da Silva et al. 2013), Provocative Synthesis II involved interactions among professional musicians and laypeople. Previous experiments focusing on creative activities outside of musical venues reported difficulties in drafting participants for the tasks. This was not the case in this experiment. During the activities, Ferreira et al. (2015) observed that a majority of store visitors were curious and interested in participating in the experience. While novices are generally reluctant to get involved in musical activities with non-musicians, the possibility of participating in a music making activity with experienced musicians may have sparked their interest.

Implications of case 2: Despite the promising avenue opened by these initial results, several difficulties still need to be addressed. Given the amount of equipment involved, technical preparations become tricky. The multi-user mixer is an effective bridge to integrate instrumental sources with ubiquitous music tools, such as mixDroid. But the dependence on wires and plugs compromises the portability of the system. A combination of wireless connectivity and software-based multi-user mixing might help to increase the mobility of the setup (see section on IoMusT).

An important flag raised by this experiment is the potential exploration of an inclusive form of social engagement involving both proficient partners and casual participants in ubiquitous musical activities. The high ratings given to the collaboration factor indicate that both musicians and untrained subjects felt they were contributing effectively to the musical result. Neither the characteristics of the settings nor the creative products conform to the expected patterns of a professional musical experience. Hence, these results cannot be classified as a professional-creativity musical outcome (cf. Keller et al. 2014a for a theoretical discussion of this issue). Furthermore, the high level of collaboration reported here was not observed in other everyday creative activities (Keller et al. 2013; Keller and Lima 2016; Pinheiro da Silva et al. 2013). The results may be interpreted as an indication that the musical experiences at the fringe of professional and everyday creativity open opportunities for effective contributions both from musicians and novices (more on this in the general discussion).

\section{Case 3: Behavioral ecologies in multimodal design}

Keller et al. (2014) report results of a ten-month design study targeting the observation of creative artistic practice by a video-artist, a sculptor and a composer. The study yielded the multimedia installation Palafito/Palafita/Home- 
on-stilts 1.0, featuring 19:30 minutes of sonic material and video footage, and three 5x8x3-meter raw-wood sculptures. Data on the procedural dimensions of the asynchronous, ubiquitous group activities carried out by the three subjects through light-weight, off-the-shelf infrastructure was extracted from a virtual forum and a file repository.

According to Keller et al. (2015), creative exchanges encompass four types of activity: dialogic, reflective, epistemic and enactive ${ }^{5}$ activities. Dialogic activities involve conceptual exchanges among agents within the context of creative endeavors. They include three types of verbal exchanges: (1) proposals exchanges that point to new processes or products within the epistemic space; (2) rejections - exchanges that exclude proposals from the epistemic space; (3) commitments - exchanges that introduce proposals within the epistemic space. Reflective activities encompass the production of concepts without triggering material exchanges. This category separates conceptual exchanges from the actions that target exchanges of material resources among the stakeholders. Periods of dialogic activity that do not involve exchanges of resources are thus labeled as reflective activities. Epistemicactivity features the exchange of textual, visual and sonic materials targeting the increase of knowledge of the epistemic space rather than the direct production of creative objects. These actions serve to materialize the concepts employed throughout the creative process, involving both creative surrogates and materials. Keller et al. (2015) define creative surrogates (or c-surrogates) as conceptual externalizations by means of information technology objects. C-surrogates and materials differ in their function. Materials are intended to be part of the creative product. C-surrogates are just scaffolds used to ground the creative process. C-surrogates may be pictures, sounds, text descriptions or software that depict procedural relationships among materials or processes. Their purpose is to serve as proxies for the exchange of information during collective decision making.

Subjects: The participants were two females - a video-artist and a sculptor - and a male composer. The three subjects were experts in their respective fields, only the composer had formal training in music.

Settings and materials: The audiovisual source materials were obtained in an ecocompositional journey that encompassed several locations within the Ecuadorean and Peruvian Amazon tropical forest (Keller 2004). The raw materials served as anchors (Keller et al. 2010) for the elaboration of the sculptural, visual, and sonic elements utilized in the piece. The experience of the

\footnotetext{
${ }^{5}$ Another term used to describe activities that yield creative products is "executive". Executive may be more appropriate when the creative activity involves strategies that rely on abstract or symbolic manipulations.
} 
journey provided the social grounding for the conceptual relationships later developed in the sounds, the visuals and the text. By adopting the artists' usual working settings, the introduction of disruptive environmental factors was avoided. Technological support was incorporated through cycles of demandtrial-assessment. Priority was given to repurposing of existing resources as opposed to development from scratch (Flores et al. 2014).

Procedures: Throughout a ten-month period, the three subjects' creative activities were monitored using two tools: a virtual forum and a file-exchange repository. The virtual platforms used were Evernote and Google Groups for argumentation and Dropbox for epistemic and enactive activities. Creative exchanges encompassed three types of activity: argumentation (a form of dialogic activity involving verbal exchanges) and epistemic and enactive activities. Argumentation was done mostly through asynchronous dialogs (only two encounters were carried through video-conference). Epistemic activity encompassed the exchange of textual, visual and sonic materials. This form of dialog was complementary to the process of argumentation and served to materialize the concepts being considered. Enactive activity involved the exchange of material that was intended to be part of the work. Therefore, only the materials that were approved through an argumentation cycle of proposals and commitments and that were labeled as acceptable creative products by at least one of the artists were considered to be the outcomes of enactive activity. For the purpose of analysis three types of resource transfers were considered: (1) proposals - concepts and materials that were not previously explicitly stated within the domain of the creative work; (2) commitments - explicit approval of proposals ensuing incorporation of new procedures or products; (3) rejections explicit exclusion of proposals from the creative epistemic space.

Creative activity results: The data analyzed in this section comes from two sources: (1) a virtual forum where the three artists exchanged ideas while developing the work (these exchanges took the form of text messages and pictures); (2) a file-exchange repository which served to gather audiovisual materials, creative support surrogates (temporal maps and low-resolution video footage), creative products and technical information consisting of plans, pictures of designs and equipment specifications.

The data extracted from the virtual forum included: a time stamp, the name of the contributor, and the content of the message. The data retrieved from the file repository encompassed: a time stamp, the name of the contributor, the name of the resource, the type of resource (either material, c-surrogate or product) and the operation applied (upload, download, move or rename). Data was formatted as tabulated text files and irrelevant entries were removed. The following selection criteria were applied to filter the data: (1) only proposals, 
commitments and rejections were included in the argumentation database; (2) only uploads of materials, surrogates or products were added to the activity database. Adopting the definitions provided in the previous section, the data analysis provides the overall profile of the activities realized during the creative process. The reflective activities took place during the first 190 days; these activities focused on the exchange of concepts but had no material counterparts. Epistemic activities involved trading creative surrogates and materials. These activities lasted 99 days. The remaining 15 days were dedicated to enactive activities featuring the elaboration and sharing of creative products.

Dialogic activity: Argumentation was done mostly through asynchronous dialogs (only two encounters were carried through video-conference). Three types of exchanges were considered: (1) proposals - concepts and materials that were not previously explicitly stated within the domain of the creative work; (2) commitments - explicit approval of proposals ensuing incorporation of new procedures or products; (3) rejections - explicit exclusion of proposals from the creative epistemic space. Dialogic exchanges that took place between 23 January and 31 October 2012. Most dialogic exchanges were proposals, followed by commitments and rejections. The dialogic activity profile of each subject provides information on the level of engagement in the argumentation process. Subject 2's commitments were slightly more than subject 1's (50\% vs. 38\%). Subject 1's percentage of rejections was slightly larger (56\% vs. $44 \%$ ). The sharpest difference corresponded to the percentage of proposals: subject 2's share almost doubled subject 1's share (32\% vs. 61\%). Three types of exchanges were considered: rejections, commitments and proposals. Although there is a tendency to alternate between categories - one or two proposals followed by one or two commitments or by one rejection - this trend only lasts until October 4 (when enactive activity starts). At that point, a new pattern is set: subject 1 almost exclusively exchanges proposals and subject 2 alternates between commitments and rejections.

Epistemic and enactive activity: During the design of Palafito 1.0, Calc/Open Office spreadsheets were repurposed to be used as proxies for audiovisual media, configuring the c-surrogates. Within Palafito 1.0's design cycle, epistemic exchanges lasted a period of 99 days while enactive activities were limited to 15 days. Interactions occurred as exchange cycles of c-surrogates, materials or products, each cycle lasting from 1 to 6 days.

A summary of the number of exchanges during epistemic and enactive activities shows that less than half of the enactive activities involved exchange of materials. Most actions were either exchanges of c-surrogates or exchanges of creative products. Product sharing was balanced, but most of the c-surrogate proposals were initiated by subject 2 (87\%). A complementary analysis comparing each artist's exchange profile shows sharp individual differences. 
While subjects 1's contributions were mostly products (67\%), subject 2's sharing featured $51 \%$ of c-surrogates. For subject 2, products $(28 \%)$ were less prominent than c-surrogates. The only similarity among the two subjects' performances was the little importance given to materials (13\% for subject 1 and $21 \%$ for subject 2 ). C-surrogates accounted for $20 \%$ of subject 1 's contributions.

Implications of case 3: The analysis of the creative exchange indicated cycles of activity alternating between reflection, exploratory action and product-oriented action. The participants were engaged in reflective activities $63 \%$ of the time, epistemic activities spanned $33 \%$ of the study and product-oriented activities accounted for only $4 \%$ of the creative design cycle. Dialogic activities did not follow a regular pattern, but a relationship between enactive and dialogic activities was observed. The sharp differences in duration between reflective, epistemic and enactive activities observed in this study provide support for the proposal that off-line cognitive resources may play an important role in shaping creative action. These results may be applied as guidelines for design. According to Wakkary and Maestri (2008), design for reflection should emphasize situated participation, non-rational design strategies, in situ design and a reorientation in focus from tasks to experience.

The temporal patterns observed in epistemic and enactive activities support the notion that potentials and resources interact defining the yield of creative processes and products. Both subjects' epistemic and enactive activities can be characterized by cycles lasting from 1 to 6 days. Dialogic activities did not follow the same pattern. Therefore, this study indicates that the mechanisms that drive epistemic and enactive activities are not necessarily applicable to social interactions in creative contexts. Another observation drawn from the temporal data of the three types of activity is a monotonic decrease from reflective to epistemic activity durations and from epistemic to enactive activity durations.

\section{1 - General discussion of the case studies}

We have laid out and discussed three applications of ubimus research, targeting a diverse set of methodological and conceptual issues. The first study handled the implications of music making in everyday contexts by casual participants. Results indicate that the time tagging creativity support metaphor furnishes an effective strategy for sound mixing in everyday settings. The second study involved the participation of musicians and novices in improvisatory sessions. The musical activities took place at a commercial venue, an audio and musical equipment store. Despite the high-level of engagement of the untrained participants, we identified several methodological shortcomings. The complexity 
of the setup - involving several pieces of equipment - reduces the portability of the system and demands a long period of preparation. Furthermore, the use of a recorded rhythmic soundtrack has a negative impact on the range of possible musical outcomes. The third study targeted the longitudinal analysis of collaborative activities by three artists, during the elaboration of a multimodal installation. The temporal patterns observed in epistemic and enactive activities support the notion that potentials and resources interact defining the yield of creative processes and products. Both subjects' epistemic and enactive activities can be characterized by cycles lasting from 1 to 6 days. Dialogic activities do not follow the same pattern. Therefore, this study indicates that the mechanisms that drive epistemic and enactive activities are not necessarily applicable to social interactions in creative contexts. Another observation drawn from the temporal data of the three activity types is a monotonic decrease of the durations from long periods of reflective activity to shorter periods of epistemic activity and to even shorter enactive activity durations.

Limitations: Ubimus experiments can be criticized from three angles. The first criticism entails the number of subjects involved in the activities. Studies have ranged from one to 67 subjects. Longitudinal studies in musical creativity usually demand detailed observations of multiple activities in various contexts. The profile of the participants is an important factor. Thus, unless the studies include subjects from diverse cultural backgrounds and with varied educational and musical experiences, the conclusions have to be limited to the profile of the target population. Given this constraint, it makes sense to carry out multiple smallsized studies (subject-wise). As long as the methods are kept consistent, general conclusions can be drawn through meta-analyses of the various small-scale studies.

The second criticism targets the data-gathering process. Although this is a valid concern, it needs to be placed within the context of the current efforts to increase the ecological validity of the experimental designs. Human-computer interaction literature has adopted a loose interpretation of the term "in the wild." For instance, experimental designs with full access to network resources, wireless support and unconstrained use of electrical power have been described as experiments in the wild. Some ubimus studies have relied on permanent access to the world wide web (Miletto et al. 2011; van Troyer 2014) while others have employed local networks (Brown et al. 2014). But experiments incorporating portable devices have bypassed the need of permanent network access or wireless support (Keller et al. 2010; Pinheiro da Silva et al 2013; Radanovitsck et al. 2011). These initiatives have dealt with a variety of settings, including transitional spaces with no electricity - such as parks and streets. The lack of electrical power did not impact the experiments negatively because the activities usually lasted less than an hour. But it is not unreasonable to expect that future 
longitudinal ubimus studies will have to deal with harsh conditions such as those found in the Amazonian jungle (Keller 2004) or in the North African desert (Burtner 2011). Hence, the data gathering techniques have to take into account multiple potential limitations - such as lack of electricity, intermittent network access or limited storage space. When targeting harsh conditions, special arrangements have to be made to ensure periodic access to ample storage space and to electrical power. Permanent network or wireless services cannot be taken for granted. Given these caveats, low-tech and highly reliable data-gathering methods - such as printed forms - sometimes may prove to be more effective than techniques that employ internet access or power-hungry devices.

The third methodological conundrum involves the choice of qualitative or quantitative techniques. Several pioneering ubimus experiments - carried out between 2007 and 2014 - have adopted a hybrid approach. Quantitative data was gathered. But given the lack of well-trodden methods, some studies have explored diverse settings and resources to identify possible drawbacks or new targets for research. This practice paid off. Several proposals featured in the Workshops on Ubiquitous Music have triggered new avenues of enquiry. Regarding the implementation of tools, the Mobile Csound Platform was featured in the 2012 UbiMus (Lazzarini et al. 2012). It has been adopted in multiple studies (Farias et al. 2014; Ferreira et al. 2015). Conceptual approaches such as the patterns for musical interaction - were also proposed and discussed in the ubimus workshops (Flores et al. 2010; Flores et al. 2012). They have been applied as strategies for classification of mobile tools for music making (Young 2012). Innovative artistic paradigms - for instance, ecologically grounded creative practices - were also proposed as a focus for ubimus research during the ubimus workshops (Keller 2014). They have been taken up by practitioners outside of the ubimus community (Aliel and Fornari 2013; Connors 2015). Eventually, exploratory methods are superseded by targeted and quantifiable data collection protocols. Recent proposals indicate two trends. On one hand, refined tools for data gathering seem to be necessary to foster health and human development applications of ubimus (Timoney et al. 2015). It is possible that physiological sensors will serve as effective complements to on-site observations and subject-based questionnaires. On the other hand, longitudinal studies might demand long-term data gathering procedures to elucidate the mechanics of artistic decision making (Keller et al. 2014). Aesthetic heuristics has emerged as an area of research within ubimus studies (Keller et al. 2015). This line of enquiry targets two aspects of the creative process. One aspect is related to the personal resources involved in creative decision making; hence it deals with time-based interactions among material and cognitive resources. The other aspect entails the study of social and situated creative actions, involving shared resources and observing how the stakeholders' actions impact decision making processes and 
how the settings constrain and foster opportunities for creative outcomes. Given the multiplicity of factors, it stands to reason that a combination of strategies may be necessary - including subjective assessments, data-gathering throughout the activities and third-party assessments of the creative products.

\section{2 - The wider scene: Implications for creativity-centered music theories}

Restating the question formulated in the introduction, do the proposed musical creativity models consider creative factors beyond the domain-specific aspects? The three proposals included in this paper - the perception-analysissynthesis model, the In-group, Out-group model and the ecologically grounded approach (Ferraz and Keller 2014; Keller 2012; Keller and Lazzarini 2017; Keller et al. 2014; Mannis 2014) - provide partial answers to this issue. All of them tackle musical creativity as a construct that does not rely exclusively on domain-specific factors. This is refreshing when compared to current musical interaction approaches that adopt acoustic-instrumental characteristics as validation criteria (Tanaka 2009; Wessel and Wright 2002). In contrast with the acousticinstrumental paradigm, the proposed concepts do not depend on simplified representations of musical materials. Therefore, they are applicable to instrumental practices, to concert-oriented electroacoustic formats and to other forms of music making - encompassing performance art, multimedia installations and the emergent use of everyday technological devices. The creative magnitudes of the three studies address everyday creativity (case 1), professional creativity (case 3) and a mix of pro-c and little-c (case 2). Case 1 features a creativity support strategy - time tagging - applicable to various stakeholders' profiles, as demonstrated by its usage in pro-c activities (Keller et al. 2009) and in little-c activities (Pinheiro da Silva et al. 2013). Despite the application of a support method - the creative surrogates - within a professional context, case 3 deals with knowledge transfer among non-musicians and musicians. Therefore, we can conclude that this support strategy does not demand domain-specific knowledge. The only activity requiring musical knowledge was the instrumental improvisation featured in case 2. This situation was particularly problematic. On one hand, the instructions for musicians had to be sufficiently specific so that the performers would have enough information to establish a common ground for decision making. The preparation for the activity included verbal hints on the type of pitch material. A rhythmic reference was laid out on a percussion-based soundtrack. This strategy may work well for one session, but it is hardly applicable as a solution for knowledge sharing among musicians and novices. Hence, a pressing problem unveiled in this experiment is 
how to promote support strategies that target the needs of both musically untrained and trained stakeholders.

What variables can be observed through the deployment of musical creativity models? The proposals discussed in this paper employ observables to gauge the predictive power of the underlying creativity mechanisms. Mannis (2014) puts forth mimesis as a key strategy for creative music making. This concept can be easily tested in experimental studies involving musicians or laypeople. The support strategy targeted by the studies discussed in case 1 - time tagging - employs local sound cues to assist the aesthetic decision-making processes. This usage of mimesis confirms the validity of the core theoretical proposal but questions the model's domain of application. Mimesis does not seem to be restricted to social interactions, it also encompasses the use of environmental features as material support for cognitive operations.

Keller's (2012) and Jones and coauthors' (2012) suggestion that creative activities involve at least four types of operations can be assessed through observational studies. The procedures utilized in case 3 are applicable to this proposal. Nevertheless, an issue not addressed by the proposed models is whether there are structural mechanisms for knowledge transfer or if the participants adopt opportunistic strategies that resist formalization.

Another notion that can be tested through experimental procedures is the concept of creative waste. The hypotheses related to waste production by trained musicians and by laypeople demand comparative studies that entail detailed observations of resource usage and disposal. In this case, a setup similar to the one used in case 2 - involving recordings of the sonic outcomes - might prove effective. But, of course, the methodological limitations observed in this study need to be addressed before adopting the procedure for other contexts.

Finally, the issue of replicability gets particularly tricky when considering creative manifestations. A creative outcome at one instance of an experiment tends to wear off its value at a second or third instance. A strategy described as original in one context might become repetitive or inadequate when transposed to other situations. Therefore, the requirement of replicability has to be reconsidered when dealing with creative activities. Case 1 provides a good example of replication of procedures. Time tagging was employed effectively in different settings and by participants with varied profiles. Contrastingly, the methods laid out in case 2 seem to be inadequate for fast deployments. An important limitation is the time for preparation required by the use of specialized audio devices. In the same vein, the data-gathering protocol adopted in case 3 may prove useful for remote asynchronous creative activities but it may not be well suited for synchronous collocated activities. Data tends to grow rapidly when all verbal and gestural interactions are recorded. As suggested by 
Mumford et al. (2011), multiple strategies may be necessary to assess activities that entail both synchronous and asynchronous interactions.

The concepts and the range of applications explored in ubimus research highlight the need of renewed approaches to music theory. As it has become clear from the issues raised by the three experimental studies discussed in this paper, ubiquitous music theory should not only engage with musical products. It also needs to deal with musical activities. A more fluid dialog with creativity studies would involve targeting both creative processes and products. Until now, music theory and music analysis have dealt with professional manifestations of creative practice, giving emphasis to eminent creativity. These manifestations rely heavily on domain-specific knowledge. Consequently, the literature on music theory has mostly been concerned with describing, explaining and supporting activities done by professional musicians. Ubimus research uncovers an uncharted field of study involving the participation of musically untrained stakeholders, musical activities that take place outside of artistic venues and resources that previously were not deemed worthy of consideration for artistic goals. This new field of study encompasses recent technological advances that push the limits of what is understood as creative music making, as it is the case with the manifestations of everyday musical creativity and the use of the Internet of Musical Things. The widespread presence of technology in our everyday life fosters fresh opportunities for creative intervention but at the same time presents challenges that were unknown to pre-internet and pre-embedded computing societies. How should personal behavioral data be handled? What are the ethical implications of collectively sharing individual choices and personal preferences? The massive availability of musical products enabled by the internet is progressively being matched by the enhanced access to creative support platforms by non-musicians. While wide access to musical activities does not necessarily entail a positive social impact (the production and rapid distribution of fake news can be cited as a negative byproduct of a massively connected global society), several ubimus projects have shown that it is possible to equate technological development with socially responsible usage.

\section{Acknowledgements}

This research was partially supported by a CNPq Productivity Fellowship (Damián Keller) and by a Maynooth University Grant (Victor Lazzarini). 


\section{References}

1. Aliel, Luzilei; Fornari, José. 2013. Creating an ecologically modeled performance through the remote manipulation of multiple soundscapes. In: E. Ferneda; G. Cabral; D. Keller (eds.). Proceedings of the XIV Brazilian Symposium on Computer Music (SBCM 2013). Brasília, DF: SBC.

2. Baer, John. 2015. The importance of domain-specific expertise in creativity. Roeper Review 37 (3), p. 165-178. (Doi: 10.1080/02783193.2015.1047480.)

3. Barrett, Natasha. 2000. A compositional methodology based on data extracted from natural phenomena. In: Proceedings of the International Computer Music Conference (ICMC 2000), p. 20-23. Ann Arbor, MI: MPublishing, University of Michigan Library.

4. Basanta, Adam. 2010. Syntax as sign: The use of ecological models within a semiotic approach to electroacoustic composition. Organised Sound 15 (2), p. 125132. (Doi: 10.1017/S1355771810000117).

5. Beghetto, Ronald A.; Kaufman, James C. 2007. Toward a broader conception of creativity: A case for "mini-c" creativity. Psychology of Aesthetics Creativity and the Arts 1 (2), p. 73-79. (Doi: 10.1037/1931-3896.1.2.73).

6. Brown, Andrew R.; Stewart, Donald; Hansen, Amber; Stewart, Alanna. 2014. Making meaningful musical experiences accessible using the iPad. In: D. Keller, V. Lazzarini; M. S. Pimenta (eds.). Ubiquitous Music, p. 65-81. Heidelberg Berlin: Springer International Publishing. (ISBN: 978-3-319-11151-3).

7. Bryan-Kinns, Nick. 2004. Daisyphone: The Design and Impact of a Novel Environment for Remote Group Music Improvisation. In: Proceedings of the 5th Conference on Designing Interactive Systems: Processes, Practices, Methods, and Techniques (DIS'04), p. 135-144. ACM. (ISBN: 1-58113-787-7).

8. Burnard, Pamela; Younker, Betty A. 2004. Problem-solving and creativity: Insights from students' individual composing pathways. International Journal of Music Education 22, p. 59-76.

9. Cádiz, Rodrigo F. 2012. Musical creation in the post-digital era (Creación musical en la era postdigital). Aisthesis 52, p. 449-475.

(Doi: 10.4067/S0718-71812012000200023). 
10. Capasso, Ariadna; Keller, Damian; Tinajero, Patricia. 2000. The Urban Corridor / Corredor Urbano [Ubiquitous Music Work]. Boulder, CO: CU Galleries.

11. Capasso, Ariadna; Keller, Damian; Tinajero, Patricia. 2004. Sysiphus 1.0 [Multimedia Installation] (Sísifo 1.0 [Instalação Multimídia]). New York, NY: General Consulate of Argentina.

12. Capasso, Ariadna; Keller, Damian; Tinajero, Patricia. 2005. Green Canopy 1.0 [Sound Sculpture]. Kingston, NY: Kingston Biennial.

13. Capasso, Ariadna; Keller, Damian; Tinajero, Patricia. 2012. Palafito / Palafita / Home-on-stilts 1.0 [Ubiquitous Music Work]. New York, NY: Floor4Art.

14. Capasso, Ariadna; Keller, Damian; Tinajero, Patricia. 2013. Palafito / Palafita / Home-on-stilts 2.0 [Ubiquitous Music Work]. Denver, CO: Museum of the Americas.

15. Capasso, Ariadna; Keller, Damian; Tinajero, Patricia. 2013. Green Canopy 6.0 [Ubiquitous Music Work]. Denver, CO: Museum of the Americas.

16. Capasso, Ariadna; Keller, Damian; Tinajero, Patricia. 2014. InMesh 1.0 / Enmarañados 1.0 / Emaranhados 1.0 [Ubiquitous Music Work]. MediaNoche Gallery, New York, NY.

17. Carroll, Erin A.; Latulipe, Celine; Fung, Richard; Terry, Michael. 2009. Creativity factor evaluation: Towards a standardized survey metric for creativity support. In: Proceedings of the Seventh ACM Conference on Creativity and Cognition, p. 127-136. Berkeley, CA: ACM. (ISBN: 978-1-60558-865-0).

18. Coelho de Souza, Rodolfo; Faria, Regis. 2012. Creativity as an emergent property in algorithmic composition (A Criatividade como Propriedade Emergente na Composição Algorítmica). In: D. Keller, D. Quaranta; R. Sigal (eds.). Sonic Ideas, Vol. Musical Creativity. México, DF: CMMAS.

19. Connors, Teresa M. 2015. Audiovisual installation as ecological performativity. In: Proceedings of the 21st International Symposium on Electronic Art (ISEA2015). Vancouver, Canada: ISEA.

20. Cope, David. 2004. Virtual music: Computer synthesis of musical style. Cambridge, MA: MIT Press. (ISBN: 9780262532617). 
21. Di Scipio, Agostino. 2008. Émergence du son, son d'emergence: Essai d'épistémologie expérimentale par un compositeur. Intellectica 48-49, p. 221-249.

22. Di Scipio, Agostino. 2014. The place and meaning of computing in a sound relationship of man, machines, and environment. In A. Georgaki ; G. Kouroupetroglou (eds.), Proceedings of the ICMCISMCI2014. Athens, Greece: ICMA.

23. Donald, Merlin. 2006. Art and cognitive evolution. In: M. Turner (ed.), The Artful Mind, p. 3-20. Oxford, UK: Oxford University Press. (ISBN: 9780195306361) 24. Dougherty, Dale. 2012. The Maker Movement. Innovations: Technology, Governance, Globalization (7), p. 11-14. (Doi: 10.1162/INOV_a_00135).

25. Dunbar, Robin I. M. ; Shultz, Susanne. 2007. Evolution in the social brain. Science 317 (5843), p. 1344-1347. (Doi: 10.1126/science.1145463).

26. Eaglestone, Barry; Ford, Nigel; Brown, Guy J.; Moore, Adrian. 2007. Information systems and creativity: An empirical study. Journal of Documentation 63 (4), p. 443-464. (Doi: 10.1108/00220410710758968).

27. Emmerson, Simon. 2001. From Dance! to "Dance": Distance and Digits. Computer Music Journal 25 (1), p. 13-20. (Doi: 10.1162/014892601300126070).

28. Fantauzzacoffin, Jill; Rogers, Juan D. 2013. Considering patterns of creative work process in creativity support. In: Proceedings of the ACM CHI Conference on Human Factors in Computing Systems (CHI'13). New York, NY: ACM.

29. Farias, Flávio M.; Keller, Damián; Pinheiro da Silva, Floriano; Pimenta, Marcelo; Lazzarini, Victor; Lima, Maria Helena de; Costalonga, Leandro; Johann, Marcelo. 2014. Everyday musical creativity support: mixDroid second generation (Suporte para a criatividade musical cotidiana: mixDroid segunda geração). In: D. Keller; M. H. Lima; F. Schiavoni (eds.), Proceedings of the $V$ Workshop on Ubiquitous Music (V UbiMus). Vitória, ES: Ubiquitous Music Group.

30. Ferraz, Silvio; Keller, Damián. 2014. Preliminary proposal of the In-group, Out-group model of collective creation (MDF: Proposta preliminar do modelo dentro-fora de criação coletiva). Cadernos de Informática 8 (2), p. 57-67.

31. Ferreira, Edemilson.; Keller, Damián; Lima, Maria Helena. 2015. Sonic sketches in ubiquitous music: Educational perspectives (Esboços sonoros em 
KELLER, Damián; LAZZARINI, Victor. 2017. Theoretical Approaches to Musical Creativity: The Ubimus Perspective. MUSICA THEORICA. Salvador: TeMA, 201701, p. 1-53.

música ubíqua: Perspectivas educacionais). Sonic Ideas 8 (15). Morelia, México: CMMAS.

32. Fitzmaurice, George; Ishii, Hiroshi; Buxton, William. 1995. Bricks: Laying the foundations for graspable user interfaces. In: Proceedings of the ACM SIGCHI Conference on Human Factors in Computing Systems (CHI'95), p. 442-449.

33. Flores, Luciano; Miletto, Evandro; Pimenta, Marcelo; Miranda, Eduardo; Keller, Damián. 2010. Musical interaction patterns: Communicating computer music knowledge in a multidisciplinary project. In: Proceedings of the 28th ACM International Conference on Design of Communication, p. 199-206. New York, NY: ACM. (ISBN: 978-1-4503-0403-0).

34. Flores, Luciano; Pimenta, Marcelo; Keller, Damián. 2014. Patterns of musical interaction with computing devices. Cadernos de Informática 8 (2), p. 68-81.

35. Gibson, James J. 1977. The theory of affordances. In: R. Shaw; J. Bransford (eds.). Perceiving, Acting, and Knowing: Toward an Ecological Psychology, p. 67-82. Mahwah, NJ: Lawrence Erlbaum Associates. (ISBN: 9780470990148).

36. Gibson, James J. 1979. The ecological approach to visual perception. Boston, MA: Houghton Mifflin. (ISBN: 0898599598).

37. Glăveanu, Vlad P. 2013. Rewriting the language of creativity: The Five A's framework. Review of General Psychology 17 (1), p. 69-81. (Doi: 10.1037/a0029528).

38. Gomes, José Alberto; Pinho, Nuno; Lopes, Filipe; Costa, Gustavo; Dias, Rui; Tudela, Diogo; Barbosa, Álvaro. 2014. Capture and transformation of urban soundscape data for artistic creation. Journal of Science and Technology of the Arts 6 (1), p. 97-109.

39. Hamman, Michael. 2002. From technical to technological: The imperative of technology in experimental music composition. Perspectives of New Music 40 (1), p. 92-120.

40. Harris, Yolande. 2009. Taking soundings: A composers' investigations into technologies of navigation. In: Conference Proceedings of MutaMorphoses: Challenging Arts and Sciences. Retrieved from:

http://mutamorphosis.wordpress.com/2009/03/03/taking-soundings-a-composerosinvestigations-into-technologies-of-navigation/ 
41. Hiller, Lejaren; Isaacson, Leonard. 1959. Experimental music: Composition with an electronic computer. York, NY: McGraw-Hill.

42. Huang, Yinghui; Li, Guanyu. 2010. Descriptive models for Internet of Things. In: International Conference on Intelligent Control and Information Processing (ICICIP 2010), p. 483-486. Dalian, China: IEEE.

43. Hutchins, Edwin. 2005. Material anchors for conceptual blends. Journal of Pragmatics 37, p. 1555-1577.

44. Hutchins, Edwin. 2010. Cognitive ecology. Topics in Cognitive Science 2 (4), p. 705-715. (Doi: 10.1111/j.1756-8765.2010.01089.x).

45. Ishii, Hiroshi; Mazalek, Ali; Lee, Jay. 2001. Bottles as a minimal interface to access digital information. In Extended Abstracts on Human Factors in Computing Systems (CHI '01), p.187-188. New York, NY: ACM. (ISBN: 1-58113-340-5).

46. Jones, Daniel; Brown, Andrew; d'Inverno, Mark. 2012. The extended composer. In: J. McCormack; M. d'Inverno (eds.). Computers and Creativity, p. 175203. Berlin and Heidelberg: Springer. (ISBN: 978-3-642-31726-2).

47. Kahneman, Daniel. 1973. Attention and Effort. Upper Saddle River, New Jersey: Prentice-Hall. (ISBN: 0-13-050518-8).

48. Katz, Shira Lee; Gardner, Howard. 2012. Musical materials or metaphorical models? A psychological investigation of what inspires composers. In: D. Hargreaves, D. Miell; R. MacDonald (eds.). Musical imaginations: Multidisciplinary perspectives on creativity, performance and perception, p. 107-123. Oxford, UK: Oxford University Press. (ISBN: 9780199568086.)

49. Kaufman, James; Baer, John. 2005. Creativity Across Domains: Faces Of The Muse. L. Erlbaum Associates. (ISBN: 9780805846577).

50. Kaufman, James; Beghetto, Ron A. 2009. Beyond big and little: The four c model of creativity. Review of General Psychology 13 (1), p. 1-12.

51. Keller, Damián. 1998. "... soretes de punta.". In: Harangue II [Compact Disc]. New Westminster, BC: earsay productions. Retrieved from: https://earsaymusic.bandcamp.com/track/soretes-de-punta 
52. Keller, Damián. 1999a. touch'n'go: Ecological Models in Composition. Master of Fine Arts Thesis, Burnaby, BC: Simon Fraser University. Retrieved from: http://www.sfu.ca/sonic-studio/srs/EcoModelsComposition/Title.html

53. Keller, Damián. 1999b. touch'n'go / toco y me voy [Compact Disc]. New Westminster, BC: earsay productions. Retrieved from: http://www.earsay.com/soundshop/earsay/CDs/tng.html

54. Keller, Damián. 2000. Compositional processes from an ecological perspective. Leonardo Music Journal 10, p. 55-60. (Doi: 10.1162/096112100570459).

55. Keller, Damián. 2001. Social and perceptual dynamics in ecologically based composition. Electronic Musicological Review 6. Retrieved from:

http://www.rem.ufpr.br/_REM/REMv6/Keller/SPD.html

56. Keller, Damián. 2004. Paititi: A Multimodal Journey to El Dorado. Doctor in Musical Arts Thesis, Stanford University, CA, USA.

57. Keller, Damián. 2011. Creativity in ubiquitous music: First impressions (Criatividade em música ubíqua: primeiras impressões). In: Proceedings of the II Workshop on Ubiquitous Music (Anais do II Workshop em Música Ubíqua - II UbiMus). Florianópolis, SC: Grupo de Música Ubíqua.

58. Keller, Damián. 2012. Sonic Ecologies. In: Andrew R. Brown (ed.). Sound Musicianship: Understanding the Crafts of Music, p. 213-227. Newcastle upon Tyne, UK: Cambridge Scholars Publishing. (ISBN: 978-1-4438-3912-9).

59. Keller, Damián. 2013. Prologue / La mano en la masa de la creatividad musical / A mão na massa da criatividade musical. Special Volume Sonic Ideas, Musical Creativity 10. Morelia, México: CMMAS.

60. Keller, Damián. 2014. Characterizing resources in ubimus research: Volatility and rivalry. In: Proceedings of the $V$ Workshop in Ubiquitous Music (V UbiMus). Vitória, ES: Ubiquitous Music Group.

61. Keller, Damián. 2015. Behavioural ecologies in ubimus. In: Proceedings of the VI Workshop on Ubiquitous Music (VI UbiMus). Växjö, Sweden: Ubiquitous Music Group.

62. Keller, Damián; Barreiro, Daniel; Queiroz, Marcelo; Pimenta, Marcelo. 2010. Anchoring in ubiquitous musical activities. In: Proceedings of the International 
Computer Music Conference, p. 319-326. Ann Arbor, MI: MPublishing, University of Michigan Library.

63. Keller, Damián; Barros, Ana Elisa B.; Farias, Flávio M.; Nascimento, Rafael V.; Pimenta, Marcelo; Flores, Luciano; Miletto, Evandro; Radanovitsck, Eduardo A. A., Serafini, Rafael O. ; Barraza, José F. 2009. Ubiquitous music: Concept and background (Música ubíqua: Conceito e motivação). In: Proceedings of the National Association of Music Research and Post-Graduation Congress - ANPPOM, p. 539-542. Goiânia, GO: ANPPOM.

64. Keller, Damián; Berger, Jonathan. 2001. Everyday sounds: Synthesis parameters and perceptual correlates. In: Proceedings of the VIII Brazilian Symposium on Computer Music (SBCM 2001). Fortaleza, CE: SBC.

65. Keller, Damián; Capasso, Ariadna. 2000. Social and perceptual processes in the installation "The Trade". Organised Sound 5 (2), p. 85-94.

(Doi: 10.1017/S1355771800002053).

66. Keller, Damián; Capasso, Ariadna. 2006. New concepts and techniques in ecocomposition. Organised Sound 11 (1), p. 55-62.

(Doi: 10.1017/S1355771806000082).

67. Keller, Damián; Capasso, Ariadna; Tinajero, Patricia. 2014. Ecologically grounded creative practice (Prácticas creativas cognitivo-ecológicas). In: D. Keller: M. A. Scarpellini (eds.). Proceedings of the III International Music Symposium in the Amazon (SIMA 2014), Vol. 2. Rio Branco, AC: EdUFAC.

68. Keller, Damián; Capasso, Ariadna; Tinajero, Patricia; Flores, Luciano V.; Pimenta, Marcelo S. 2009. Green Canopy: On The Road [Ubiquitous Music Work]. In: Proceedings of XII Brazilian Symposium on Computer Music (SBCM 2009). Porto Alegre, RS: SBC.

69. Keller, Damián; Feichas, Leonardo. 2016. Ecocompositional and performative strategies for creative usage of everyday sounds: Introducing creative semantic anchoring. In: Proceedings of The Balance Unbalance Conference (BunB 2016). Manizales, Colombia: University of Caldas.

70. Keller, Damián; Ferreira da Silva, Edmilson; Pinheiro da Silva, Floriano; Lima, Maria Helena; Pimenta, Marcelo; Lazzarini, Victor. 2013. Everyday musical creativity: An exploratory study with vocal percussion (Criatividade musical cotidiana: Um estudo exploratório com sons vocais percussivos). In: Proceedings 
of the National Association of Music Research and Post-Graduation Congress ANPPOM. Natal, RN: ANPPOM.

71. Keller, Damián; Flores, Luciano V.; Pimenta, Marcelo S.; Capasso, Ariadna; Tinajero, Patricia. 2011. Convergent trends toward ubiquitous music. Journal of New Music Research 40 (3), 265-276. (Doi: 10.1080/09298215.2011.594514).

72. Keller, Damián; Lazzarini, Victor. 2017. Ecologically grounded creative practices in ubiquitous music. Organised Sound (22), p. 61-72.

(Doi: $10.1017 / S 1355771816000340)$.

73. Keller, Damián; Lazzarini, Victor; Pimenta, Marcelo S. (eds.). 2014. Ubiquitous Music, Vol. XXVIII. Berlin and Heidelberg: Springer International Publishing. (ISBN: 978-3-319-11152-0).

74. Keller, Damián; Lazzarini, Victor; Pimenta, Marcelo S. 2014. Ubimus through the lens of creativity theories. In: D. Keller; V. Lazzarini; M. S. Pimenta (eds.). Ubiquitous Music, p. 3-23. Berlin and Heidelberg: Springer International Publishing. (ISBN: 978-3-319-11151-3).

75. Keller, Damián; Lima, Maria Helena. 2016. Supporting everyday creativity in ubiquitous music making. In: P. Kostagiolas; K. Martzoukou; C. Lavranos (eds.). Trends in Music Information Seeking, Behavior, and Retrieval for Creativity. Vancouver, BC: IGI Global Press.

76. Keller, Damián; Lima, Maria Helena; Pimenta, Marcelo S.; Queiroz, Marcelo. 2011. Assessing musical creativity: Material, procedural and contextual dimensions. In: Proceedings of the National Association of Music Research and PostGraduation Congress - ANPPOM, p. 708-714. Uberlândia, MG: ANPPOM.

77. Keller, Damián; Miletto, Evandro M.; Otero, Nuno. 2015. Creative surrogates: Supporting decision-making in ubiquitous musical activities. In: Proceedings of the 3rd International Conference on Computation, Communication, Aesthetics and $\mathrm{X}$ ( $x$ CoAx 2015). Glasgow, Scotland: xCoAx.

78. Keller, Damián; Ferneyhough, Brian. 2004. Analysis by Modeling: Xenakis's ST/10-1 080262. Journal of New Music Research 33 (2), p. 161-171.

(Doi: 10.1080/0929821042000310630). 
79. Keller, Damián; Otero, Nuno; Costalonga, Leandro L. 2015. Aesthetic heuristics in ubimus. In: Proceedings of the Electronic Visualisation and the Arts Conference (EVA 2015). London: BCS, Computer Arts Society Specialist Group.

80. Keller, Damián; Otero, Nuno; Lazzarini, Victor; Pimenta, Marcelo S.; Lima, Maria Helena; Johann, Marcelo; Costalonga, Leandro. 2014. Relational properties in interaction aesthetics: The ubiquitous music turn. In: K. Ng; J. P. Bowen; S. McDaid (eds.). Proceedings of the Electronic Visualisation and the Arts Conference (EVA 2014). London: BCS, Computer Arts Society Specialist Group.

Retrieved from: http://ewic.bcs.org/content/ConMediaFile/24235

81. Keller, Damián; Otero, Nuno; Lazzarini, Victor; Pimenta, Marcelo S.; Lima, Maria Helena; Johann, Marcelo; Costalonga, Leandro L. 2015. Interaction aesthetics and ubiquitous music. In: N. Zagalo; P. Blanco (ed.). Vol. Creativity in the Digital Age, p. 91-105. Berlin and Heidelberg: Springer.

(ISBN: 978-1-4471-6680-1). Retrieved from:

http://link.springer.com/chapter/10.1007\%2F978-1-4471-6681-8_6\#

82. Keller, Damián; Timoney, Joseph; Costalonga, Leandro; Capasso, Ariadna, Tinajero, Patricia; Lazzarini, Victor; Pimenta, Marcelo S.; Lima, Maria Helena; Johann, Marcelo. 2014. Ecologically grounded multimodal design: The Palafito 1.0 study. In: Proceedings of the International Computer Music Conference (ICMC 2014). Ann Arbor, MI: MPublishing, University of Michigan Library.

83. Keller, Damián; Truax, Barry. 1998. Ecologically based granular synthesis. In: Proceedings of the International Computer Music Conference, p. 117-120. Ann Arbor, MI: MPublishing, University of Michigan Library.

84. Kirsh, David; Maglio, Paul. 1994. On distinguishing epistemic from pragmatic action. Cognitive Science 18 (4), p. 513-549.

85. Kozbelt, Aaron; Beghetto, Ronald A.; Runco, Mark A. 2010. Theories of creativity. In: J. C. Kaufman; R. J. Sternberg (eds.). The Cambridge Handbook of Creativity, The Cambridge Handbook of Creativity, p. 20-47. Cambridge, UK: Cambridge University Press. (ISBN: 9780521730259).

86. Laske, Otto E. 1989. Composition theory: An enrichment of music theory. Interface 18 (1-2), 45-59. (Doi: 10.1080/09298218908570537).

87. Laske, Otto E. 1991. Toward an epistemology of composition. Interface 20 (34), p. 235-269. (Doi: 10.1080/09298219108570593). 
KELLER, Damián; LAZZARINI, Victor. 2017. Theoretical Approaches to Musical Creativity: The Ubimus Perspective. MUSICA THEORICA. Salvador: TeMA, 201701, p. 1-53.

88. Lazzarini, Victor. 2013. The development of computer music programming systems. Journal of New Music Research 42 (1), p. 97-110.

(Doi: 10.1080/09298215.2013.778890).

89. Lazzarini, Victor; Costello, Edward; Yi, Steven; ffitch, John. 2014. Development tools for ubiquitous music on the world wide web. In: D. Keller; V. Lazzarini; M. S. Pimenta (eds.). Ubiquitous Music, p. 111-128. Heidelberg Berlin: Springer International Publishing. (ISBN: 978-3-319-11151-3).

90. Lazzarini, Victor; Keller, Damian; Kuhn, Carlos; Pimenta, Marcelo; Timoney, Joseph. 2015. Prototyping of ubiquitous music ecosystems. Journal of Cases on Information Technology 17 (4). (Doi: 10.4018/JCIT.2015100105).

91. Lazzarini, Victor; Keller, Damián; Pimenta, Marcelo; Timoney, Joseph. 2014. Ubiquitous music ecosystems: Faust programs in Csound. In: D. Keller; V. Lazzarini; M. S. Pimenta (eds.). Ubiquitous Music, p. 129-150. Berlin and Heidelberg: Springer International Publishing. (ISBN: 978-3-319-11151-3).

92. Lazzarini, Victor; Yi, Steven; Timoney, Joseph; Keller, Damián; Pimenta, Marcelo S. 2012. The Mobile Csound Platform. In: Proceedings of the International Computer Music Conference, p. 163-167. Ann Arbor, MI: MPublishing, University of Michigan Library.

93. Lima, Maria Helena; Keller, Damián; Otero, Nuno; Pimenta, Marcelo S.; Lazzarini, Victor; Johann, Marcelo; Costalonga, Leandro. 2014. Ecocompositional techniques in ubiquitous music practices in educational settings: Sonic sketching. In: E. Himonides; A. King (eds.). Proceedings of the SEMPRE (MET2014): Researching Music, Education, Technology: Critical Insights, p. 123-127. London: iMerc.

94. Lima, Maria Helena; Keller, Damián; Pimenta, Marcelo S.; Lazzarini, Victor; Miletto, Evandro M. 2012. Creativity-centred design for ubiquitous musical activities: Two case studies. Journal of Music, Technology and Education 5 (2), p. 195222. (Doi: 10.1386/jmte.5.2.195_1).

95. Löwgren, Jonas. 2009. Toward an articulation of interaction esthetics. New Review of Hypermedia and Multimedia 15 (2), p. 129-146.

(Doi: 10.1080/13614560903117822). 
96. Lubart, Todd. 2005. How can computers be partners in the creative process: Classification and commentary on the special issue. International Journal of Human-Computer Studies 63 (4-5), p. 365-369. (Doi: 10.1016/j.ijhcs.2005.04.002).

97. Luce, David A. 1963. Physical correlates of nonpercussive musical instrument tones. Doctoral Thesis in Physics, Massachusetts Institute of Technology, Department of Physics. Retrieved from: http://hdl.handle.net/1721.1/27450

98. Mannis, José Augusto. 2014. Cognitive processes of perception, analysis and synthesis during the creative process: Mimesis of mimesis (Processos cognitivos de percepção, análise e síntese atuando no processo criativo: Mímesis de mímesis). In: Anais do Encontro Nacional de Composição Musical de Londrina (EnCom 2014). Retrieved from:

http://www.academia.edu/11616845/Processos_cognitivos_no_Processo_criativo__M\%C3\%ADmesis_de_M\%C3\%ADmesis.

99. Marsden, Alan. 2012. "What was the question?": Music analysis and the computer. In: L. Gibson; T. Crawford (eds.). Modern Methods for Musicology: Prospects, Proposals, and Realities, p. 137-153. London: Ashgate Publishing. (ISBN: 9781409486039).

100. McCormack, Jon. 2012. Creative Ecosystems. In: J. McCormack; M. s'Inverno (eds.). Computers and Creativity, p. 39-60). Berlin, Heidelberg: Springer. (ISBN: 978-3-642-31726-2).

http://www.gold.ac.uk/computing/staff/m-dinverno/

101. McCormack, Jon; d'Inverno, Mark. 2012. Computers and Creativity. Berlin, Heidelberg: Springer. (ISBN: 978-3-642-31726-2).

102. McGlynn, Patrick; Lazzarini, Victor. 2012. Multitouch data analysis for expressivity in musical performance (Análise de dados multitoque para expressividade em performance musical). In: D. Keller; D. Quaranta; R. Sigal (eds.). Sonic Ideas, Vol. Musical Creativity 10. México, DF: CMMAS.

103. McGraw, Gary; Hofstadter, Douglas. 1993. Perception and creation of diverse alphabetic styles. AISB Quarterly 85, 42-49.

104. Miletto, Evandro M.; Pimenta, Marcelo S.; Bouchet, François; Sansonnet, Jean-Paul; Keller, Damián. 2011. Principles for music creation by novices in networked music environments. Journal of New Music Research 40 (3), 205-216. (Doi: 10.1080/09298215.2011.603832). 
KELLER, Damián; LAZZARINI, Victor. 2017. Theoretical Approaches to Musical Creativity: The Ubimus Perspective. MUSICA THEORICA. Salvador: TeMA, 201701, p. 1-53.

105. Mitchell, William J.; Inouye, Alan S.; Blumenthal, Marjory S. 2003. Beyond Productivity: Information Technology, Innovation, and Creativity. Washington, DC: The National Academies Press.

106. Mumford, Michael D.; Hester, Kimberly; Robledo, Issac. 2011. Methods in creativity research: Multiple approaches, multiple methods. In M. D. Mumford (ed.). Handbook of Organizational Creativity, p. 39-64. Waltham, MA: Elsevier Science. (ISBN: 9780080879109).

107. Nance, Rick W. 2007. Compositional explorations of plastic sound. Doctoral Thesis in Music, De Montfort University, UK.

108. Newell, Allen; Shaw, John C.; Simon, Herbert. 1958. The processes of creative thinking. Santa Monica, CA: Rand Corporation.

109. Nierhaus, Gerhard. 2009. Algorithmic Composition. Vienna: Springer. (ISBN: 9783211755402).

110. Norman, Don A. 1988/2013. The design of everyday things. New York, NY: Basic Books.

111. O'Callaghan, James. 2013. Orchestration of ecology, as ecology. In: Proceedings of the Symposium Music and Ecologies of Sound: Theoretical and Practical Projects for a Listening of the World. Paris, France: University of Paris 8.

112. Odling-Smee, F. John; Laland, Kevin; Feldman, Marcus 2003. Niche Construction: The Neglected Process in Evolution. Princeton, NJ: Princeton University Press. (ISBN: 9780691044378).

113. Opie, Timothy; Brown, Andrew. 2006. An introduction to eco-structuralism. In: Proceedings of the International Computer Music Conference (ICMC 2006), p. 9-12. Ann Arbor, MI: MPublishing, University of Michigan Library.

114. Pereira, Vanessa S.; Silva, Simone L.; Bessa, William R. B.; Alcântara-Silva, Tereza R.; Keller, Damián. In press. SoundSphere: Participatory design as a strategy to develop sustainable tecnologies in ubiquitous music (SoundSphere: $\mathrm{O}$ design participativo como estratégia para o desenvolvimento de tecnologias sustentáveis em música ubíqua). Sonic Ideas. Morelia, México: CMMAS. 
115. Pimenta, Marcelo S.; Keller, Damián; Flores, Luciano V.; Lima, Maria Helena; Lazzarini, Victor. 2014. Methods in creativity-centred design for ubiquitous musical activities. In: D. Keller, V. Lazzarini; M. S. Pimenta (ed.). Ubiquitous Music, p. 25-48. Springer International Publishing. (ISBN: 978-3-319-11152-0).

116. Pimenta, Marcelo S.; Miletto, Evandro M.; Keller, Damián; Flores, Luciano V. 2012. Technological support for online communities focusing on music creation: Adopting collaboration, flexibility and multiculturality from Brazilian creativity styles. In: N. A. Azab (ed.). Cases on Web 2.0 in Developing Countries: Studies on Implementation, Application and Use. Vancouver, BC: IGI Global Press. (ISBN: 1466625155).

117. Pinheiro da Silva, Floriano; Keller, Damián; Ferreira da Silva, Edmilson; Pimenta, Marcelo S.; Lazzarini, Victor. 2013. Everyday musical creativity: Exploratory study of ubiquitous musical activities (Criatividade musical cotidiana: Estudo exploratório de atividades musicais ubíquas). Música Hodie 13, p. 64-79.

118. Quiñones, Marta G., Kassabian, Anahid; Boschi, Elena (eds.), 2013. Ubiquitous musics: The everyday sounds that we don't always notice. London: Ashgate Publishing Company. (ISBN: 9781409451334).

119. Radanovitsck, Eduardo A. A.; Keller, Damián; Flores, Luciano V.; Pimenta, Marcelo S.; Queiroz, Marcelo. 2011. mixDroid: Time tagging for creative activities (mixDroid: Marcação temporal para atividades criativas). In: L. Costalonga; M. S. Pimenta; M. Queiroz; J. Manzolli; M. Gimenes; D. Keller; R. R. Farias (eds.). Proceedings of the XIII Brazilian Symposium on Computer Music (SBCM 2011). Vitória, ES: SBC.

120. Rhodes, Mel. 1961. An analysis of creativity. The Phi Delta Kappan 42, p. 305311.

121. Ribeiro Netto, Ayer; Castheloge, Luan; Oliosi, Amanda; Mateus, Ariane; Costalonga, Leandro; Coura, Daniel. 2015. Memory Tree: Multimedia Interactive Installation (Árvore das Memórias: Instalação Multimídia Interativa). In: Proceedings of the XV Brazilian Symposium on Computer Music (SBCM 2015), p. 7683. Campinas, SP: SBC. Retrieved from:

http://nescom.ufes.br/instala\%C3\%A7\%C3\%A3o-\%C3\%A1rvore-da-mem \%C3\%B3ria

122. Richards, Ruth. 2007. Everyday creativity and the arts. World Futures 63 (7), p. 500-525. (Doi: 10.1080/02604020701572707). 
KELLER, Damián; LAZZARINI, Victor. 2017. Theoretical Approaches to Musical Creativity: The Ubimus Perspective. MUSICA THEORICA. Salvador: TeMA, 201701, p. 1-53.

123. Richards, Ruth; Kinney, Dennis; Benet, Maria; Merzel, Ann. 1988. Assessing everyday creativity: Characteristics of the lifetime creativity scales and validation with three large samples. Journal of Personality and Social Psychology 54, p. 476-485.

124. Rogers, Yvonne. 2014. Mindless or mindful technology? In: Proceedings of the 2014 ACM Symposium on Engineering Interactive Computing Systems (SIGCHI 2014), p. 241-241. ACM. (ISBN: 978-1-4503-2725-1).

125. Runco, Mark A. 2004. Creativity. Annual Review of Psychology 55 (1), p. 657687. (Doi: 10.1146/annurev.psych.55.090902.141502).

126. Runco, Mark A. 2007. A hierarchical framework for the study of creativity. New Horizons in Education 55 (3), p. 1-9.

127. Schaeffer, Pierre. 1977. Traité des objets musicaux: Essai interdisciplines. Paris: Éditions du Seuil. (ISBN: 9782020026086).

128. Schafer, R. Murray. 1977. The Tuning of the World. New York, NY: Knopf.

129. Shneiderman, Ben. 2007. Creativity support tools: accelerating discovery and innovation. Communications of the ACM 50 (12), p. 20-32. (Doi: 10.1145/1323688.1323689).

130. Silva, Simone L.; Keller, Damián; Pereira, Vanessa S.; Bessa, William R. B. 2016. Creativity assessment strategies with children: Using emoticons in time tagging activities (Estratégias de aferição da criatividade com público infantil: Utilizando ícones faciais em atividades com a metáfora de marcação temporal). In: Proceedings of the Amazon International Sympoisum on Music (SIMA 2016). Belém, PA: EMUFPA.

131. Simonton, Dean K. 1990. History, chemistry, psychology, and genius: An intellectual autobiography of historiometry. In: M. A. Runco; R. S. Albert (eds.). Theories of Creativity, p. 92-115. Newbury Park, CA: Sage.

132. Spielkermann, Sarah. 2011. About the "Idea of Man" in system design - An enlightened version of the Internet of Things? In: D. Uckelmann; M. Harrison; F. Michahelles (eds.). Architecting the Internet of Things, p. 1-24. Berlin and Heildelberg: Springer. 
133. Sweller, John. 1988. Cognitive load during problem solving: Effects on learning. Cognitive Science 12 (2), p. 257-285. (Doi: 10.1207/s15516709cog1202_4).

134. Tanaka, Atau. 2009. Sensor-based musical instruments and interactive music. In: R. T. Dean (ed.). The Oxford Handbook of Computer Music, p. 233-257. New York, NY: Oxford University Press. (ISBN: 9780195331615).

135. Truax, Barry. 2002. Genres and techniques of soundscape composition as developed at Simon Fraser University. Organised Sound 7 (1), p. 5-14. (Doi: 10.1017/S1355771802001024).

136. Truax, Barry. 2015. Paradigm shifts and electroacoustic music: Some personal reflections. Organised Sound 20, p. 105-110.

(Doi: 10.1017/S1355771814000491).

137. Turchet, Luca; Fischione, Carlo; Barthet, Mathiew. 2017. Towards the Internet of Musical Things. In: Proceedings of the Sound and Music Computing Conference (SMC2017). Helsinki, Finland: Aalto University.

138. Uckelmann, Dieter; Harrison, Mark; Michahelles, Florian. 2011. An architectural approach towards the future Internet of Things. In: D. Uckelmann; M. Harrison; F. Michahelles (eds.). Architecting the Internet of Things, p. 1-24. Berlin and Heildelberg: Springer.

139. Upton, Catherine; Eaglestone, Barry; Ford, Nigel. 2005. The compositional processes of electroacoustic composers: Contrasting perspectives. In Proceedings of the International Computer Music Conference (ICMC 2005). Ann Arbor, MI: MPublishing, University of Michigan Library.

140. van Kranenburg, Rob; Bassi, Alessandro. 2012. IoT Challenges. Communications in Mobile Computing 1 (1), p. 9. (Doi: 10.1186/2192-1121-1-9).

141. van Troyer, Akito. (2014). Repertoire remix in the context of Festival City. In: D. Keller; V. Lazzarini; M. S. Pimenta (eds.). Ubiquitous Music, p. 51-63. Berlin and Heidelberg: Springer International Publishing. (ISBN: 978-3-319-11152-0).

142. Wakkary, Ron; Maestri, Leah. 2008. Aspects of everyday design: Resourcefulness, adaptation, and emergence. International Journal of HumanComputer Interaction 24 (5), p. 478-491. (Doi: 10.1080/10447310802142276). 
143. Wallas, Graham. 1926. The art of thought. New York: Harcourt, Brace and Company.

144. Weiser, Mark; Brown, John S. 1996. Designing calm technology. Powergrid Journal 1.

Retrieved from: http://www.ubiq.com/hypertext/weiser/calmtech/calm tech.htm

145. Wenger, Etienne. 2010. Communities of practice and social learning systems: The career of a concept. In: C. Blackmore (ed.). Social Learning Systems and Communities of Practice, p. 179-198. Springer London. (ISBN: 978-1-84996-132-5).

146. Wessel, David; Wright, Matthew. 2002. Problems and prospects for intimate musical control of computers. Computer Music Journal 26 (3), p. 11-22.

(Doi: 10.1162/014892602320582945).

147. White, Paul. 2010. JamHub: Personal monitor system. Sound On Sound.

Retrieved from http://www.soundonsound.com/sos/oct10/articles/jamhub.htm

148. Wilson, Margaret. 2002. Six views of embodied cognition. Psychonomic Bulletin \& Review 9 (4), p. 625-636. (Doi: 10.3758/BF03196322).

149. Windsor, William L. 1995. A perceptual approach to the description and analysis of acousmatic music. Doctoral Thesis in Music, London: City University.

150. Wishart, Trevor. 2009. Computer music: Some reflections. In: R. T. Dean (ed.), The Oxford Handbook of Computer Music, p. 151-160. New York, NY: Oxford University Press. (ISBN: 9780195331615).

151. Young, Samson. 2014. Laboratory for ubiquitous musical expression. Hong Kong: The City University of Hong Kong. Retrieved from:

http://www.connecting spaces.ch/ubiquitous-musical-expression/ 